ADA-90-2092.

Contract Number: DE-AC01-90CE27500

\title{
ENERGY CONSERVATION ST ANDARDS FOR NEW FEDERAL RESIDENTIAL BUILLDINGS: A DECISION ANALYSIS STUDY USING RELATIVE VALUE DISCOUNTING
}

FINAL REPORT

\section{Prepared for:}

Dr. Fred Abel

Office of Buildings and Community Systems

Conservation and Renewable Energy

U.S. Department of Energy

Prepared by:

Dr. Charles Harvey

College of Business Administration

University of Houston

Houston, IX 77204-6282

Dr. Miley M. Merkhofer

Dr. Greguiy L. Hamm

Applied Decisi on Analysis. Inv. 3000 Sand Hill Road, Suite 4-255

Menlo Park, CA 94025

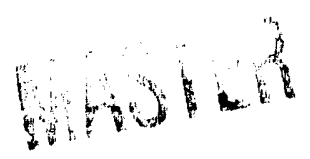

July 2, 1990 DETPIBUTION OF THIS DOCUMENT IS LNLIMITED 


\title{
Contents
}

1. Previous Analysis of the Proposed Standard for Energy Conservation 3

2. This Report's Preliminary Analysis of the Proposed Standard 6

3. Social Tradeoffs Between Present Costs and Future Benefits 12

4. Social Benefits of Fuel Savings 18

5. The Benefit-Cost Ratio as a Criterion for Public Policy Evaluation 23

References $\quad 29$

Appendix A: Calculation of the Spreadsheet Information Used in this Report 31

Appendix B: Decision Analysis 43

\section{DISCLA.IMER}

\begin{abstract}
This report was prepared as an account of work sponsored by an $a_{2}$ ncy of the United States Government. Neither the United States Government nor any agency thereof, nor any of their employees, makes any warranty, express or implied, or assumes any legal liability or responsibility for the accu'acy, completeness, or usefulness of any information, apparatus, product, or process disclosed, or represents that its use would not infringe privately owned rights. Refer ence herein to any specific commercial product, process, or service by trade name, trademark, manufacturer, or otherwise does not necessarily constitute or imply its endorsement, resom. mendation, or favoring by the United States Government or any agency thereor. The views and opinions of author: expressed herein do not necessarily state of reflect those of the United States Government or any agency thereof.
\end{abstract}




\section{Introduction}

This report presents a reassessment of the proposed standard for energy conservation in new federal residential buildings. The analysis uses the data presented in the report, Economic: Analysis: In Support of Interim Energy Conservation Standards for New Federal Residenital Buildings (June 1988)-to be referred to as the EASIECS report. Our reassessment differs from that report in several respects. In modeling factual information, it uses more recent forecasts of future energy prices and it uses data from the Bureau of the Census in order to estimate the distribution of lifetimes of residential buildings rather than assuming a hypothetical 25 -year lifetime for all residential buildings. In modeling social preferences, it uses techniques from the discipline of decision analysis in order to examine issues of public values that often are not included in traditional cost-benefit analyses.

Because a major part of this report is a reassessment of the EASIECS report-indeed, a reassessment that leads to a significantly different recommendation-this report may appear to be critical of the EASIECS report. In fact, we feel that the EASIECS report is quite well done 'within the confines of traditional cost-benefit methodology. What is being criticized is not the the EASIECS report but the unnecessarily limited vision of that methodology.

The cumulative effect of the changes in the analysis is to arrive at a different conclusion from that of the EASIECS report. The EASIECS report "describes the effects of requiring that all new residential buildings constructed for the federal government comply with the proposed standard. The analysis concludes that no significant impacts are expected to occur as a result of this requirement. [page 3.1]" The present report concludes, on the contrary, that the public would benefit from the proposed standard. Here, the phrase, "the public would benetit," means that if the discounted future benefits and costs of the standard are estimated and are traded off with its initial costs, then the ratio of net future benefits to initial costs is much larger than one-our estimates, with different assumptions of social values, range from 3.7 to 1 to a surprising 29.8 to 1 .

An important purpose of this report is to identify several issues of public values regarding energy use and to illustrate methods by which these issues can be included in a formal analysis of a proposed energy policy. The first such issue is that of placing a value on costs and benefits that will occur in the future-perhaps the distant future - as an irreversible consequence of current policy choices. The common method of present value discounting (used in the EASIECS report) assumes a discount rate that is constant over time. If a selected discount rate is appropriate for events in the near future, then present value discounting will place little imporiance on events in the distant future-much less importance than may seem appropriate as a reflection of our social 
responsibility for future generations. This report discusses an alternative method, called "relative value dirr sunting," that permits a more flexible discounting of future events-and the possibility of placing a much greater value on events in the distant future.

The second issue is that of placing a value on the indirect benefits of energy savings, that is, the benefits that accrue to everycne rather than only to the person who saves the energy. The EASIECS report includes only direct benefits, i.e., decreases in the monetary costs for energy use in the buildings affected by the standard. The indirect benefits include the decrease in subsidized monetary costs for energy; the reduction in the effects of air pollution on health, on plants and animals, and on materials; the gain in energy independence; the decreased contribition to the greenhouse effect; the reduction in health risks and environmental risks associated with the generation of nuclear power and the disposal of hazardous wastes; and incentives for advances in conservation technology. By excluding these indirect benefits, the EASIECS report in effect estimates them to be zero. This report includes non-zero estimates of the indirect benefits.

The third issue is that of how the costs and benefits discussed in a public policy evaluation should be compared. The EASIECS report uses as the primary criterion for the desirability of the energy conservation standard the difference between the net present value of the overall benefits to result from the standard and the net present value of the overall costs to result from the standard. They conclude that while this difference is positive, it "would be too small at the national level to be significant [page 3.8]." It is true that an institution or society that has limited resources may not be able to fully fund a!l of the projects for which the net benefits exceed the net costs. We argue that under such circumstances, the institution should use as its criterion for the selection of projects the ratio of net future benefits to initial costs rather than the difference between these two measures. In summary, the reason is that the criterion of selecting those individual projects with larger benefit to cost ratios leads to a portfolio of projects with the maximum benefit to cost difference.

Section 1 of this report presents a review of the EASIECS report. Then, Section 2 presents our reevaluation based on the information in that report concerning fuel and non-fuel costs, information from the Bureau of the Census concerning the lifetimes of residential buildings, and recent forecasts of future energy prices. This section does not consider the issues of public values mentioned above. Section 3 brings into the analysis the issue of social tradeoffs between the present and the future, and Section 4 brings into the analysis the issue of indirect social benetits of energy conservation. Section 5 compares the benefit to cost difference criterion and the benefit to cost ratio criterion and presents our conclusions based on the variety of policy and methodological positions that are discussed in the previous sections. 


\section{Previous Analysis of the Proposed Standard for Energy Conservation}

The EASIECS report analyzes some of the effects of the energy conservation standard that DOE has proposed for the design of new federal residential buildings. The standard itself is performance-based and is implemented by means of a computer program that evaluates the whole building design to arrive at a single measure of energy efficiency. The computer program takes information concerning the building type, local construction and maintenance costs, climate, and estimates of local fuel costs. It first selects from a list of prototype building designs that building type which most closely matches the proposed building and calculates the "optimum life-cycle energy cost" for the prototype building, that is, "the energy cost of the fuel type and the set of energy conservation measures that have a minimum total 25 -year life-cycle cost (including construction, maintenance, operation, and energy), .. . [page 2.2]" The program then calculates the 25-year life-cycle energy costs for the prototype building when the energy conservation measures in the proposed building are used. Compliance is established provided that "the energy conservation measures of the proposed building provide 25 -year life-cycle energy costs less than or equal to the optimal life-cycle energy costs, ... [page 2.3]" More detailed descriptions of the standard are given in the EASIECS report and in Mitnick et al. (1985).

The EASIECS report quantifies two types of costs that will be affected by the proposed Standard: the costs of fuel, and the costs of construction and maintenance, i.e., the non-fuel costs. The fuel costs and non-fuel costs are estimated for a total of 14 . building caies consisting of th: combinations of seven building prototypes, four locations in the U.S., and five types of fuel.

For each of the 140 building cases and each of the first 25 years of use of the building, first the costs are calculated assuming current building design and then the costs are calculated assuming a building design in compliance with the standard. Next, the fuel costs and the non-fuel costs are separately aggregated over the 25 year horizon by the method of present value discounting using an annual discount rate of $7 \%$ in real dollars (Technical Support Document, DOE/CE-()223, 1988, page 4.19). These costs aggregated over time are called the life-cycle fuel cost and the life-cycle non-fuel cost. For each of the 140 building cases, the following quantities are calculated:

(a) The life-cycle fuel cost with current practice minus that cost with the standard. This difference-to be called in this repor the life-cycle fuel cost difference-is interpreted as a measure of the savings in energy costs to be attained by the standard.

(b) The life-cycle non-fuel cost with the standard minus that cost with current practice. This difference-to be called in this report the life-cycle non-fuel cost difference-is interpreted as at 
measure of the extra costs of construction and maintenance needed to meet the standard.

(c) The sum of the life-cycle fuel cost and life-cycle non-fuel cost with current practice minus the sum of these costs with the standard. This difference-to be called in this report the total life. cycle cost difference-is used in the EASIECS report as the measure by which the desirability of the proposed energy conservation is judged. The EASIECS report points out that "In all cases, the total life-cycle costs were lower for the building configured to meet the standard, although in some cases the differences were insignificant. [pages 3.1-3.2]"

In the EASIECS report, the cost differences (a)-(c) are reported for all 140 building cases in Appendices A.1-A.4 and for 84 of these building cases ( 3 of the 5 fuel types) in Table 3.1 .

The next step in the EASIECS analysis is to aggregate each type of life-cycle cost difference over the 140 building cases. The Department of Defense purchases $95 \%$ of the residential buildings constructed for the federal government, and so as an approximation the class of military residential buildings is taken as representative of-indeed, equal to - the class of all federal residential buildings. At the time the EASIECS report was prepared, the forecast of the military for new residential construction was for a total of 18,500 buildings over the next five year period. It appears that estimates of the relative frequencies of the 140 building cases for this period were not available for the EASIECS report-see the discussion on page 3.3. Therefore, the EASIECS report aggregated over the 140 building cases by taking unweighted averages.

Table 3.2 in the EASIECS report provides the averages of the cost differences (a)-(c) for each of the four geographic locations, i.e., the unweighted averages over the seven building prototypes and five types of fuel. Table 3.3 reports the averages of the cost differences (a)-(c) for each of the seven building prototypes, i.e., the unweighted averages over the four geographic locations and five types of fuel. In addition, the bottom line of Table 3.2 reports the averages over all of the 14() building cases. These "national averages" are as follows.

Table 1.1. Unweighted averages of the cost differences for the 140 building cases
FCD:
The average life-cycle fuel cost difference
$\$ 2,647$
NFCD:
The average life-cycle non-fuel cost difference
$-\$ 1,230$
Total:
The total average life-cycle cost difference
$\$ 1,417$

The final step in the EASIECS analysis is to multiple these average cost differences per building by the estimated number of 18,500 military residential buildings to be constructed during the chosen five year period. These amounts are as follows: 
(a) The total savings in energy cost is $\$ 49.0$ million ( $\$ 53.2$ million in the EASIECS report).

(b) The total extra construction and maintenance cost is $\$ 22.8$ million ( $\$ 2.6 .3$ million in the EASIECS report).

(c) The total of the cost differences is a net benefit of $\$ 26.2$ million ( $\$ 27$ million in the EASIECS report).

As indicated above, our arithmetic led to somewhat different results than those reported on page 3.8 of the EASIECS report. We do not know what is the cause of these discrepancies. They are not sufficiently large to have any important effect on our further analysis in this report.

The net benefit of $\$ 27$ million is used as the basis for the overall conclusion of the EASIECS report. That conclusion is stated on page 3.8 as follows: "This net figure of $\$ 27$ million, if it was an accurate estimate of the annual effect, would be too small at the national level to be significant."

The EASIECS report also discusses several other effects of the proposed standard in addition to the direct economic effects of a decrease in fuel costs and an increase in construction and maintenance costs. These discussions of other effects are in summary as follows:

(a) Regional effects. The range in the average total life-cycle cost differences for the four geographic locations is $\$ 290$ per building which is "considerably less than one percent of the total cost. [page 3.10]" It is argued that therefore "the regional differences that would accrue as a result of adopting the proposed standard are insignificant. [page 3.10]"

(b) Industry effects. The EASIECS analysis "would suggest that building material sales, per residential unit, would be about the same, while the value of equipment sales would be slightly higher. The industry impact of these slight changes would be insignificantly small, especially in comparison with the volume of sales from the construction of the new building[s]. [page 3.12]" For the utilities industry, the "lower incremental sales would be insignificantly small in comparison with the additional revenue gained from sales to new residences. [page 3.12]"

(c) Federal government effects. The "major impact would be to reduce the life-cycle costs of new federal residential buildings. ... Again the conclusion suggested by this magnitude of effect [\$27 million] is that [the] impact is insignificant. [page 3.12]"

(d) Small business effects. "Based on the quantitative results of this study and ... PNL5120 [a study of new federal commercial buildings], it is concluded that the proposed rule would not adversely impact small businesses in any significant manner. [pages 3.12-3.13]"

(e) Nonquantifiable costs. "One is the administrative costs to federal agencies adopting the proposed standard. ... The second potential impact that is not quantified is the costs to businesses of learning and complying with the proposed standard. [page 3.13]" 


\section{This Report's Preliminary Analysis of the Proposed Standard}

This section presents a reevaluation of the EASIECS report that is based on the information in that report concerning the energy savings and the extra costs of construction and maintenance that are expected to result from the proposed standard. This reevaluation differs from the analysis in the EASIECS report in that the buildings are not assumed to last for 25 years but are assumed to have a distribution of lifetimes that is estimated from Bureau of the Census data. It also differs from the EASIECS report in that it uses more recent projections of future energy cost rates.

In other respects, the analysis in this section is as close as possible to the analysis in the EASIECS report. In particular, we consider the same two policy alternatives: to require the energy conservation standard that DOE has proposed for the design of new federal residential buildings or to continue with current practice. We do not consider, for example, an alternative in which buildings are retrofitted with energy conservation measures at some future time. Moreover, we defer discussions of the three issues of public values that are identified in the introduction.

The reevaluation of the EASIECS report in this section and the further analyses in Sections 3-5 are based on the types of information (a) $-(\mathrm{g})$ described below.

\section{(a) The distribution of housing lifetimes}

The data below was reported in the 1979 Annual Housing Survey (Part A: General Housing Characteristics, Table A.5). This data provides information on the ages of conventional housing units that were removed from the nation's housing inventory in 1973.

Table 2.1. Age at removal of U.S. conventional residential housing units

$\begin{array}{cc}\text { Age in years } & \text { Relative frequency } \\ 0-3.5 & 0.016 \\ 3.5-13.5 & 0.098 \\ 13.5-23.5 & 0.079 \\ 23.5-33.5 & 0.114 \\ >33.5 & 0.693\end{array}$

Several comments should be made on the appropriateness of this data for estimating housing lifetimes for the population of future federal residential building units. One issue is that the population of housing units described by the data consists of private housing rather than federal housing and of housing constructed in the past rather than housing to be constructed in the future. 
We conjecture that there will be only slight systematic age differences between the population of past, private housing and the population of future, federal housing. A second issue is the variation in lifetime distributions from one geographic region to another. In the Northeast, $90 \%$ of the housing units removed from inventory were at least 33 years old whereas in the South $56 \%$ of the housing units removed from inventory were at least 33 years old. For our analysis only the distribution of national housing lifetimes is considered. Thus, we are in effect assuming that it makes little difference whether one first averages lifetime distributions over the geographic regions and then calculates costs and benefits or first calculates costs and benefits for each geographic region and then averages these costs and benefits over the regions. If an analysis of the costs and benefits in each geographical region is needed as part of a future study, then the needed data is available from the Bureau of the Census.

The EASIECS report appears to model the lifetimes of residential housing units by assuming that the expected lifetime of a housing unit is 25 years and that this expected value rather than the full probability distribution is sufficient for further analysis. According to the above data, this assumption seriously understates the length of time that energy conservation measures in residential housing provide energy savings. The data implies, for example, that approximately $78 \%$ of the housing units had a lifetime of at least 25 years.

In this report, we will estimate a probability distribution of housing lifetimes from the Bureau of the Census data in Table 2.1. We will use the following notation.

$\mathrm{L}=$ the lifetime of a building, i.e., the last year $t=1,2, \ldots$ in which the building is used.

$s_{t}=$ the fraction of buildings still in use during at least half of year $t$, that is, $P(L \geq--.5)$.

In a DOE Memorandum, Holt (1989) models the data in Table 2.1 with an exponential distribution, $s_{t}=\exp (-r t)$, where the coefficient $r$ measures the "intensity" at which buildings are removed from use. Here, $r=0.01$ so that about $1 \%$ of the buildings still in use are removed during a year. With this model,the expected lifetime of a building unit is 100 years. The fit to the data is very good, having an r-squared value of 0.99 .

We wish to be cautious, however, not to overestimate the proportion $s_{t}$ of buildings having extremely long lifetimes. We will do this by considering the aging of the building so that the coefficient $r$ is not constant but increases as a linear function of $t$, that is, $r=a+b t$ with $b>0$. Thus, we will use the following family of distributions:

$$
s_{t}=P(L \geq t-0.5)=\exp (-(a+b t) t) \text { for } t=1,2, \ldots
$$

where $a>0$ and $b>0$ are the two parameters that determine the distribution. 
From the data in Table 2.1, the parameters are estimated by hand calculation to have the values $a=0.0060$ and $b=0.00014$. It follows, for example, that about $0.5 \%$ of the housing units are removed from inventory during each of the first few years. The graph of $s_{\mathfrak{t}}$ for these parameter values is shown in Figure 1.1 below. It can be calculated from the puiameter values or seen from Figure 1.1 that $79 \%$ of the housing units have a lifetime of at least 25 years and the median lifetime of a housing unit is 52 years. These amounts contrast sharply with the mean lifetime of 25 years that is assumed in the EASIECS report.

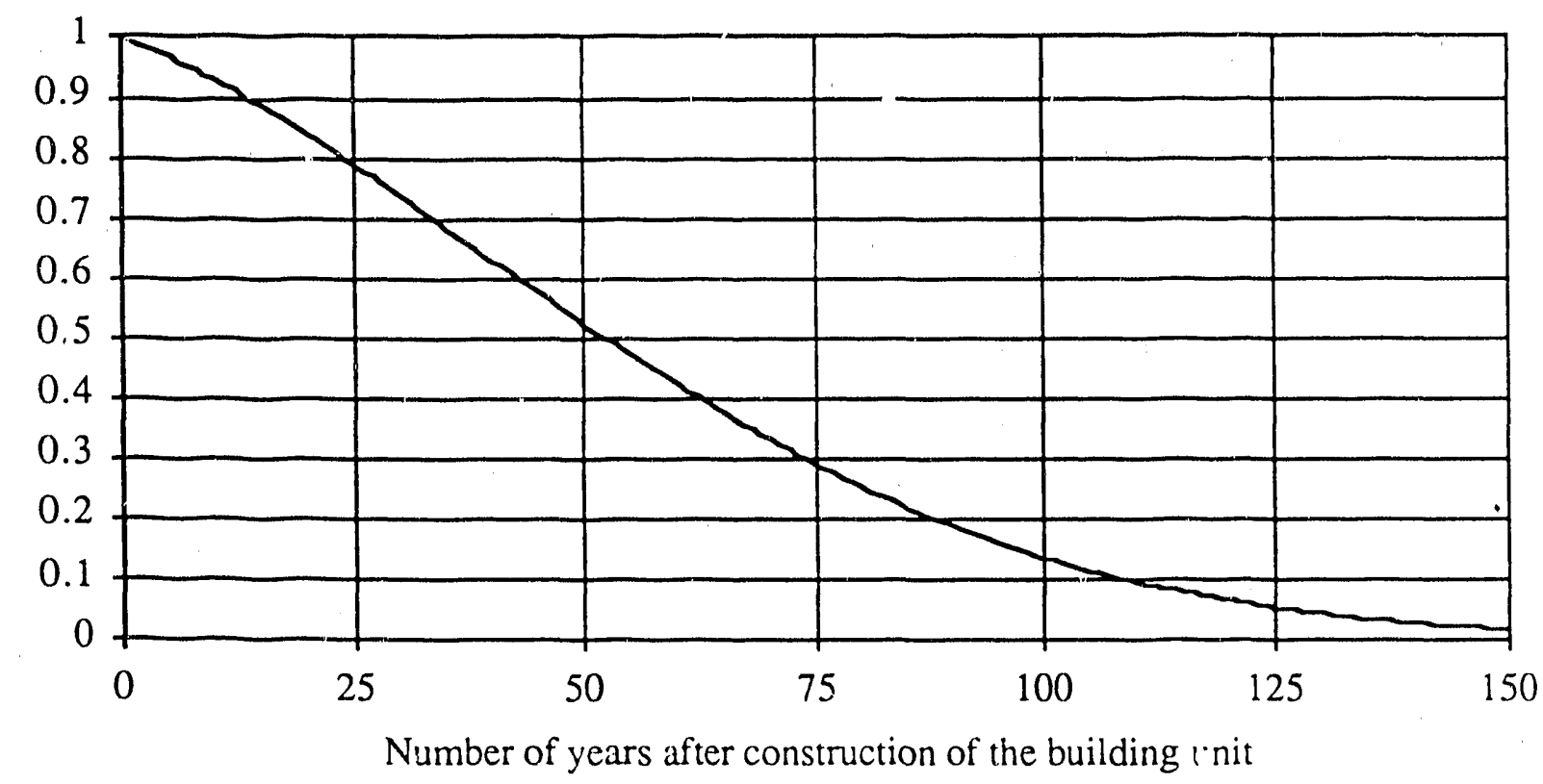

Figure 1.1. Graph of the proportion $s_{t}$ of buildings still in use in year $t$

(b) The relative frequencies of different building types in future federal residential buildings

In this report, we will weight the 140 building cases reported in the E.ASIECS report equally when determining average costs and energy savings. This assumption is a simplification, but without data on the relative frequencies of the building cases it appears to be a reasonable approach.

(c) The expected annual fuel savings measured in 1985 dollars for each of the 140 building cases

For each of the 140 building cases, the estimated fuel cost to be saved per year per building unit as a result of the conservaticn standard and assuming 1985 energy prices is estimated based on data received from the authors of the EASIECS report in personal correspondence (July 1989). These estimated monetary amounts and their calculation are described in the Appendix in this report. They will be denoted by $e_{i}, i=1, \ldots, 140$, where $i$ indexes the 140 building cases. 
(d) The yearly expected rates of energy costs measured in 1985 dollars

The direct cost per unit of energy will fluctuate from year to year for each of the five energy types. In order to calculate the expected savings in direct energy costs for a building unit during each future year, $t=1,2, \ldots$, in the lifetime of the building, we do not need to assess the probability distributions of the cost rates for each year. Instead, we only need to assess the expected cost rate for each building unit for each year.

We estimate these yearly expected rates by assuming that they will change from year to year in accord with changes in the prices of crude oil. Numerous agencies and research institutes prepare long-range forecasts of the future prices of crude oil. During the past five years, 1986-90, the International Energy Workshop at Stanford University has collected these long-range forecasts in a form suitable for comparison. The most recently collected forecasts are reported in Manne and Schrattenholzer (1990, page A-3). Their report provides medians of from twelve to twenty-one forecasts of the price per barrel of crude oil measured in constant dollars for the years 1990, 2000, and 2010. We fitted this data with a log-linear model having time as the control variable and rnedian estimated price as the response variable, and thus estimated the expected annual rate of increase in the price of crude oil to be 0.03425 , that is, about $3.4 \%$ per year. We did not include the single forecast for the year 2020. Had we done so, the expected rate would have been larger, about $4.3 \%$ per year. As it happens, the average of the rates used in the EASIECS report was $3.45 \%$. Thus, we will be using approximately the same fuel cost increases as in that report.

Suppose that for each of the 140 building cases, $i=1, \ldots, 140$, and for each future year, $t=1,2, \ldots$, the expected energy savings measured in 1985 dollars per building unit of type $i$ during year $\mathrm{t}$ is denoted by $\mathrm{e}_{\mathrm{i}}(\mathrm{t})$. Since we assume that the expected rates of all five types of energy' costs drift upward by $3.425 \%$ per year in 1985 dollars, we will use the formula

$$
e_{i}(t)=p_{t} e_{i} \text { for } i=1, \ldots, 140 \text { and } t=1,2, \ldots
$$

where $p_{t}=(1.03425)^{t-1}$ is the price escalation factor for year $t$.

(e) The extra construction and maintenance costs due to the standard

For each of the 140 building cases, the estimated extra non-fuel costs of construction and maintenance to be required per year per building unit as a result of the conservation standard can be estimated in 1985 dollars based on data in the report Technical Support Document: In Support of Interim Energy Conservation Standards for New Federal Residential Buildings (June 1988) and 
data received from the authors of the EASIECS report in personal correspondence (July 1989). These estimated costs are listed in the Appendix in this report. The initial construction costs, i.e., costs that occur during year $t=1$ are the primary non-fuel costs. They will be denoted by $c_{i}$ where $i=1, \ldots, 140$ indexes the 140 different building cases. In addition, there are maintenance costs for the replacement of equipment that occur every 15 years and every 18 years during the lifetime of the building unit. These costs also are listed in the Appendix in this report. They will be denoted by $c_{i}(15)$ and $c_{i}(18)$ respectively.

\section{(f) The timing discount factors for future costs and benefits}

In the EASIECS repurt, the value of future costs and benefits is measured by means of the method of present value discounting - the typical method for cost-benefit studies. The EASIECS report uses a discount rate of $7 \%$ in real dollars. An alternative to present value discounting that can attach greater value to future costs and benefits is discussed in the next section.

For any method of discounting future events, suppose that the weight assigned to a year $t$ is denoted by $a_{t}, t=1,2, \ldots$ With this notation, the EASIECS report uses the weights

$$
a_{t}=(1 / 1.07)^{t-1} \text { for } t=1,2, \ldots
$$

In this section, we will follow the EASIECS report by also using these weights.

(g) The indirect benefits of the energy savings due to the standard

In the EASIECS report, the indirect benefits of energy savings such as a reduction in air pollution are in effect estimated to be zero. Social benefits of this type are discussed in Section 4. In the present section, we will follow the EASIECS report by also estimating the indirect benefits to be zero.

We are now able to calculate the benefits in fuel savings and the extra non-fuel costs that are expected to result from the proposed energy conservation standard for new federal residential housing. First, we consider the expected net present value of the direct savings in fuel costs per building unit averaged over the 140 different building cases-that is, the quantity referred to in Table 1.1 as the average life-cycle fuel cost difference (FCD). In terms of the notation (1)-(3), the expected value of this benefit measured in 1985 dollars is given by the formula:

$$
F C D=\Sigma_{i}\left[\sum_{t} a_{t} s_{t} e_{i}(t)\right] / 140=\left[\sum_{t} a_{t} s_{t} p_{t}\right]\left[\sum_{i} e_{i} / 140\right]
$$


A specific value of the benefit (4) can be obtained by means of the information (a) -(g). Lsing this information, (4) can be calculated as

$$
F C D=[22.198\rfloor[187.12]=\$ 4,154
$$

Second, we consider the net present value of the extra non-fuel costs of construction and mair:enance per building unit averaged over the 140 different building cases-that is, the quantity referred in in Table 1.1 as the average life-cycle non-fuel cost difference (NFCD). In terms of the notation in (e), the expecter value of this cost measured in 1985 dollars is given by the formula:

$$
\begin{aligned}
N F C D= & \left.\Sigma_{i} c_{i} / 140+\left(a_{15} s_{15}+a_{30} s_{30}+\ldots\right) \sum_{i} c_{i}(15) / 140\right) \\
& +\left(a_{18} s_{i 8}+a_{36} s_{36}+\ldots\right) \sum_{i} c_{i}(18) / 140
\end{aligned}
$$

A specific value of tha cost (5) can be obtained by means of the cost information of type (e) on page 9. With the imin? weights (3) used in the EASIECS repor, (5) can be calculated as

$$
\mathrm{NFCD}=1059.69+(0.49) 489.85+(0.35) 86.07=\$ 1,329
$$

in Table 2.2 below, the averagc life-cycle fuel cost difference (FCD) in (4') and the average life-cycle non-fuel cost difference (NFCD) in (5') are compared with the corresponding amounts reported in the EASIECS report.

Tahle.2.2. Comparison of the analyses ir: the EASIECS report and in this section

\section{EASIECS repon This section}

The benefit (FCD)

Ti.e $\operatorname{cost}(N F C D)$

The benefit.cost difference

The benefit -cost ratio
$\$ 2,647$

$\$ 1,230$

$\$ 1,417$

2.15

$$
\$ 4,154
$$

$\$ 2,824$

3.12

The discrepancy between the benefits in energy savings that are estimated in the EASIECS report and those that are estimated in this section is due essentially to a single difference in the information used in the analyses. In this repon, the buildings are not assumed to last for 25 years but are assumed to have a distribution of lifetimes that is estimated from Bureau of the Census data. The longer lifetimes tand to increase the fuel savings benefits. 
The cost-benefit discrepancies between the two analyses are not due to any differences in the social values that are represented. Issues of social values will be discussed in the following two sections, and will be shown to lead to significant cost-benefit differences between the EASIECS report and this report.

\section{Social Tradeoffs between Present Costs and Future Benefits}

How should our government make tradeoffs between costs that occur in the present and benefits that occur in the future-perhaps in the distant future and perhaps to later gererations? Should we assign importance to the future only in accord with economic efficiency or should we also consider our responsibility for the quality of the future? This section discusses a method of including in a policy evaluation social concerns for the future that are not dictated by economic efficiency and that are excluded with the traditional method of present value discounting.

Any method of discounting the importance of future events assigns a timing weight $a_{t}$ to each cost or benefit according to the number of years $t$ from the present in which the cost or benefit occurs. Here, the ratio of two timing weights $a_{t+1} / a_{t}$ determines the tradeoffs between the costs and benefits in two adjacent years $t$ and $t+1$, and is called a discount factor.

In a present value discounting model, th. timing weights form a geometric sequence, namely,

$$
a_{t}=(1 /(1+i))^{t-1}, t=1,2, \ldots
$$

where the constant $1 /(1+i)$ is the discount factor for any two adjacent years whatever and $i$ is the corresponding social discount rate. For example, the EA.SrECS report uses a social discount rate of $\mathrm{i}=0.07$ in real dollars. The problem of assessing a social discount rate has received much attention. See, e.g., Lind et al. (1982), Mishan (1976), and Stokey and Zeckhauser (197o').

From the perspective of normative economics, this form of the timing weights is seen as an implication of the stationarity principle. This principle states that the tradeoffs between outcomes in any two years $t$ and $t+h$ should depend only on the time lapse $h$ between the years and not on the futurity $t$ of the initial year. Koopmans (1960) proved that tradeoffs satisfy the stationarity principle if and only if the timing weights have the geometric form of present value discounting.

The structure of present value discounting imposes a rigidity on tradeoffs, however, that seems to be inappropriate in two respects. First, the use of a geometric sequence of timing weights has the effect that, if the social discount rate is within the range of commonly used rates that are 
appropriate for events in the near future, then very little importance is assigned to outcomes that are in the distant future. Consider, for examiple, the policy choice discussed in this report, of whether to have an tnergy conservation standard for the design of new federal residential buildings. Here, even moderate social discount rates lead to timing weights $a_{\uparrow}$ that may be regarded as strikingly undervaluing future energy savings. For instance, if an annual discount rate of $7 \%$ is used as in the EASIECS report, then costs that occur now will be measured as five and one-half times more important than benefits which occu: in twenty-five years and as nine-hundred times more important than benefits which occur in a hundred years.

Many people would like for public policy studies to include välue judgments that assign a far greater importance to the future and to the quality of life for future generations. Thic objection to present value discounting has been discussed from several viewpoints, for example, in Fischhoff et al. (1981, page 112), Lovins (1974), and Mishan (1981, pages xv and 498-505). For those who advocate a greater concern for the future, the frustration has undoubtedly led in some instances to a distrust and rejection of the entire methodology of cost-benefit analysis.

A second objection to present value discounting has come more recently from behavioral research. Empirical studies of people's choices between consumption amounts at different times have demonstrated that most people's choices follow a pattern which systematically violates the stationarity principle. Namely, a specified time lapse between two consumption amounts is less important the farther into the future the amounts occur. For example, a person might be indifferent between receiving $\$ 100$ after one month or receiving $\$ 110$ after two months but would discard the option of receiving $\$ 100$ after one year in favor of the option of receiving $\$ 110$ after a year and a month.

This pattern of preferences is observed in Benzion, Rapoport, and Yagil (1989). Horowitz (1988), and Thaler (1981). Loewenstein and Prelec (1989) rafer to it as the common difference effect. They discuss a number of violations of discounting models that are analogous to the much more studied violations of expected utility models and observe that "Unlike EU [expected utility| violations, which in many cases can only be Jemonstrated with a clever arrangement of multiple choice problems (e.g., the Allais paradox), the counter-examples to DU [discounted utility] are simple, robust, and bear directly on central aspects of economic behavior."

Perhaps one reason for the prevalence of the present discounting method in public policy studies has been the absence of an alternative method that is tractable in practice. It is perceived as impractical to assume a general sequence of timing weights $\left\{a_{t}\right\}$ and to determine somehow each of the finite or infinite number of weights $a_{\mathfrak{l}}$.

An alternative to present value discounting has been developed that avoids both this problem 
and the objections to present value discourting that are discussed above. This method, called relative value discounting, is discussed in detail in Harvey $(1986,1988)$. Here, we summarize the main ideas.

As mentioned above, present value discounting uses the condition that a preference betweeri two consumption amounts depends only on the (absolute) time lapse between the amounts. In an analogous fashion, relative value discounting use $s$ the condition that a preference berween two consumption amounts depends only on the relative time lapse between the amounts. A person who has such preferences is said to have relative timing preferences (Harvey, 1986). For example, a person with relative timing preferences who is indifferent between receiving $\$ 100$ after one month or receiving $\$ ! 10$ after two months also would be indifferen, between receiving $\$ 100$ after one year or receiving $\$ 110$ after two years since the relative time lapse as measured from the present is the same in both cases, namely a doubling of time.

This condition can be made more flexible by noting that the relative time lapse may also be measured with respect to a time other than the present. In the above example, suppose that a person has relative timing preferences with respect to a year ago. Such a person who is indifferent between receiving $\$ 100$ at present or receiving $\$ 110$ after one month then would be indifferent between receiving $\$ 100$ after one year or receiving $\$ 110$ after a year and two months.

In a relative value discounung model, the condition of relative timing preferences is used to structure the sequence $\left\{a_{t}\right\}$ of timing weights. Relative timing preferences with respect to a time of $b$ years before the present implies that $\left\{a_{t}\right\}$ is an arithmetic sequence, namely, $(b+t)^{-r}$ for $t=1,2, \ldots$ If these timing weights are divided by the constant $(b+1)^{-r}$ in order that $a_{1}=1$, then the sequence of timing weights $\left\{\mathrm{a}_{\mathrm{l}}\right\}$ is of the form

$$
a_{t}=((b+1) /(b+t))^{-r}, t=1,2, \ldots
$$

Here, the quantities $b>0$ and $r>0$ may be regarded as parameters analogous to the single parameter $\mathrm{i}$ in a present value discounting model.

An arithmetic sequence of timing weights (7) differs from a geometric sequence of timing weights (6) in several respects. First, any weights of the form (7) decrease to zero as $t$ tends to infinity more slowly than any weights of the form (6), and thus a relative value discounting model assigns more importance to the distant future than does a present value discounting model. This is so because the ratio of the weights $((b+1) /(b+t))^{-r} /(1 /(1+i))^{t-1}$ tends to infinity as $t$ tends to infinity for any parameter amounts $b>0, r>0$, and $i>0$. 
Second, in a relative value discounting model, any absolute time lapse between two consumption amounts is less important the farther into the future the amounts occur, i.e., in the terminology of Loewenstein and Prelec (1989) there is a common difference effect. This is so because for any time lapse $h$ the discount rate $(b+t+h)^{-r} /(b+t)^{-r}$ from time $t$ to time time $t+h$ tends to unity as $t$ tends to infinity.

Both an arithmetic sequence of timing weights and a geometric sequence of timing weights are structured in the sense that the weights can be determined by determining one or two parameters. With an arithmetic sequence there is more flexibility since there are two parameters. For example, one can specify the following two quantities:

(a) A initial social discount rate $\mathrm{i}$ from year 1 to year 2 (so that $a_{2}=1 /(1+i)$ ).

(b) A temporal midvalue $\mathrm{m}$ that designates the year judged to be half as important as year 1 (so that $a_{m}=1 / 2$ ).

One can calculate the two parameters $b, r$ from the two assessed quantities $i$ and $m$. We will use this assessment procedure in this repor. The initial social discount rate $\mathrm{i}$ can be viewed as a measure of society's short-term timing preferences, and the temporal midvalue $\mathrm{m}$ can be viewed as a measure of society's long-term timing preferences.

One normative argument for modeling intertemporal tradeoffs with present value discounting models is that if a society uses such models at different times, e.g., at the years 1990 and 1995 , then provided that society chooses the same discount rate at both times the society at year 199() will have the same tradeoffs between two future tirnes, e.g., 2000 and 2010, as will the society at year 1995. This lack of a dependence of traderffs on the temporal position of society will not hold if society uses the same relative value discounting model at the years 1990 and 1995 . Then, the society at year 1990 will regard the years 2000 and 2010 as more nearly equal in importance than will the society at year 1995.

Should a normative model of intertemporal tradeoffs satisfy ihe above condition of temporal independence or should it allow for the inclusion of temporal dependence as an important aspect of social preferences? A parallel question arose several decades ago in the use of expected-utility models as normative mojels of a person's risk attitude. There, the issue was whether any such model should satisfy the condition that a person's preferences do not depend on his current financial position (the so-called cunstant risk attitude condition) or whether a model should permit the person's aversion to risk to be less if his current financial position is greater.

A second issue is that of the relationship between the social discount rate (constant or not) to 
be used in a normative model and the rates at which society can borrow or loan money. For social decisions of an investment nature, it seems reasonable the social discount rate should be between these two. For social decisions of a consumption nature, however, this recommendation does not necessarily follow. Reality dictates the options that are available to society but it does not dictate the values with which society chooses between those options. In our opinion, the expected rates for borrowing or loaning money do not and should not determine society's tradeoffs regarding consumption of goods or regarding risks to health and the environment.

Because there are these conflicts between the normative arguments for a constant discount rate and hence the use of a present value discounting model and the social and behavioral arguments for a decreasing sequence of discount rates and hence the use of a discounting model such as relative value discounting, we expect (and would encourage) a certain amount of controversy. For the use of timing models in public policy evaluation, the question to be addressed is this: Under what conditions is it appropriate to use a present value discounting model and under what conditions is it appropriate to use a discounting model such as relative value discounting that assigns a decreasing sequence of discount rates?

We are at the beginning rather than the end of any resolution of this question, but it is possible to make a few general observations. On the one hand, present value discounting seems appropriate for decisions in which the outcomes are investment allocations and returns. Since the discount rates are constant, it is not possible to model preferences that change as the present time advances, and thus there is no possibility of a temporal intransitivity-for example, a willingness to loan money at a low interest rate and a 20-year maturity and also a willingness to borrow money at a high interest rate and a 10-year maturity and ten years later to repay that loan and again borrow money at a high interest rate and a 10 -year maturity. On the other hand, relative value discounting models may be appropriate for decisions in which the outcomes are either benefits in the form of consumption of a good (and thus its disappearance) or are risks to health or to the environment. Since the discount rates are decreasing, it is possible to model preferences that can represent society's sense of generosity and responsibility for future welfare.

One criterion for determining which of the above two categories a given decision belongs to is that of irreversibility - after the decision has been made, will it be feasible to undo the decision by substituting outcomes at one time for outcomes at another time. For example, the decision of whether to design buildings that conserve energy seems to be for the most part an irreversible decision since it would be much nore expensive to retrofit the buildings with cor parable energy 
conserving measures. Moreover, the buildings may be used far into the future-for a hundred years or more. For these reasons, we believe that it is worthwhile to examine the proposed standard for energy conservation in new federal residential buildings by means of a relative value discounting mociel as well as by means of a present value discounting model.

First, we will suppose that the initial discount rate is $7 \%$ as in the EASIECS report, that is, $\mathrm{i}=0.07$, and the temporal midvalue is $\mathrm{m}=15$ years, that is, society values costs and benefits that occur in the first year to be twice as important as coits and benefits that occur fourteen years later, in the year $t=15$. Then, the timing weights are $a_{t}=14.29 /(13.29+t), t=1,2, \ldots$ A timing midvalue of $\mathrm{m}=15$ years seems not to place an inappropriately large importance on the distant future-note that the method of present value discounting with a discount rate of $5 \%$ also has a timing midvalue of about 15 years.

Second, we will suppose that the initial discount rate is $5 \%$ and the temporal midvalue is 20 years. Then, the timing weights are $a_{t}=20.0 /(19.0+t)$. The method of present value discounting with a discount rate of $3.25 \%$ also has a timing midvalue of atout 20 years.

The three sequences of timing weights used in this report are shown in Figure 3.1 below.

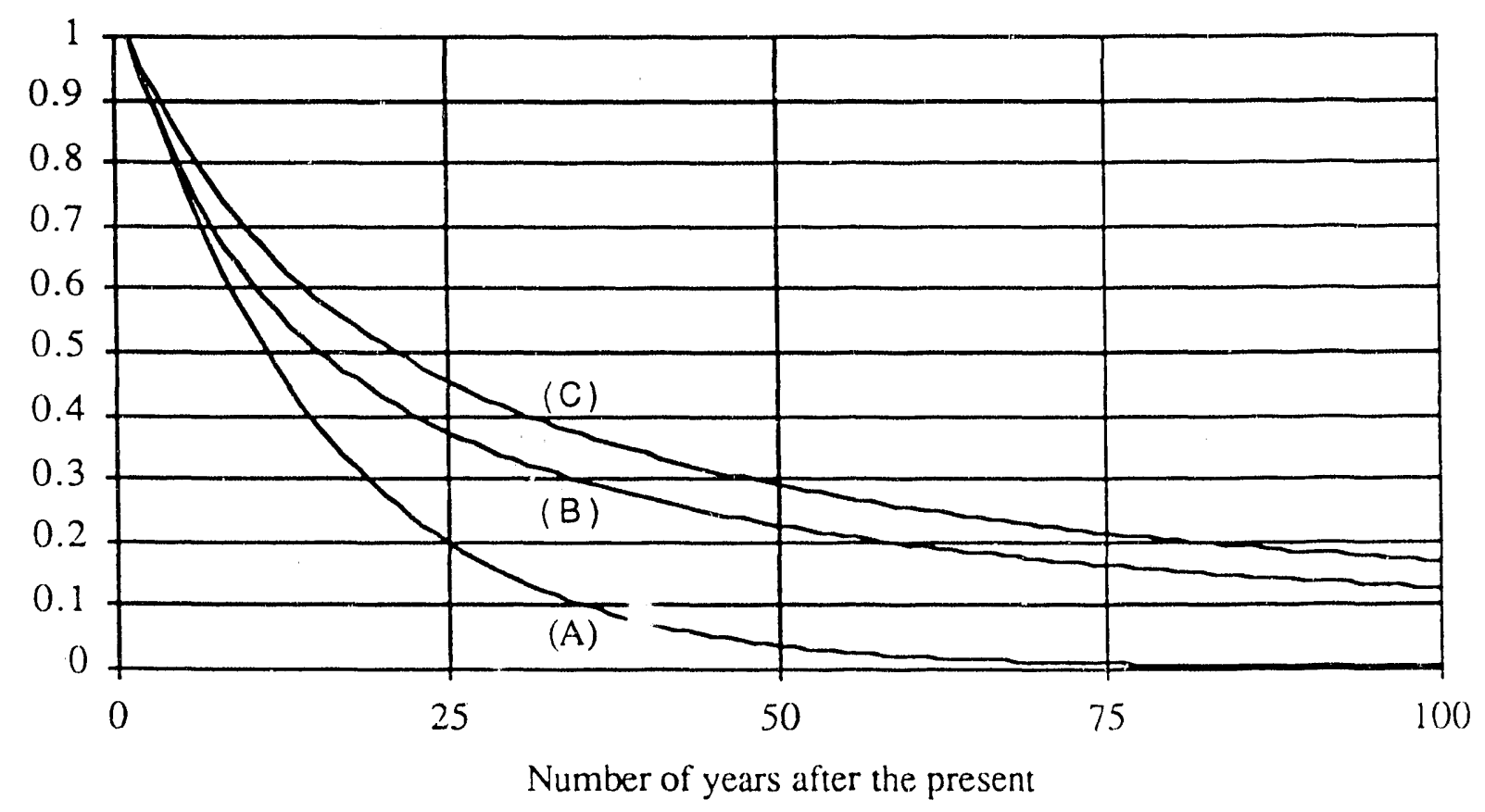

Figure 3.1. Graphs of the three sequences of timing weights $\left\{a_{t}\right\}$
(A) Present value discounting with $i=.07$
(B) Relative value discounting with $\mathrm{i}=.07$ and $\mathrm{m}=15$
(C) Relative value discounting with $\mathrm{i}=.05$ and $\mathrm{m}=20$ 
With the relative value discounting timing weights, the costs and benefits of the proposed conservation standard can be calculated by means of the formulas (4) and (5). The results are shown in Table 3.1 below.

Table 3.1. The present-value analysis in Section 2 and the relative-value analysis in this section

Present value discounting Relative value discounting with with a rate of $7 \% \quad \mathrm{i}=.07, \mathrm{~m}=15 \quad \mathrm{i}=.05, \mathrm{~m}=20$

The benefit (FCD)

$\$ 4,154$

$\$ 1,329$

The cost (NFCD)

The benefit-cost difference

The benefit-cost ratio
$\$ 2,824$

3.12
$\$ 16,216$

$\$ 1,622$

$\$ 14,595$

10.00
$\$ 21,121$

$\$ 1,750$

$\$ 19,371$

12.07

The benefit-cost ratios that are estimated in this section are far greater than those that are estimated in the EASIECS report and in the previous section. The reason is that the non-fuel costs occur primarily in the present whereas the benefits in fuel savings occur in the future. Section 5 discusses the implications for public policy of the costs and benefits reported in the above table.

\section{Social benefits of fuel savings}

How should our government estimate the indirect costs to society that are caused by the production and use of energy from fossil and nuclear fuels ? Here, the term "indirect costs" designates those costs which are not borne by the citizen who uses the energy but which devolve on all of us as consequences of the energy usage. There are two issues in this question of indirect costs. First, there is the issue of whether a public policy evaluation should exclude the indirect costs of energy because that they are not part of a laissez-faire economic process or whether it should include the indirect costs as essential parts of the consequences that our society faces when making such a decision.

On this issue, we believe that a public policy decision should depend on all of the important consequences to the people who will be affected by that decision. Hardin (1968) has elucidated those choice situations in which each member of a group faced with his or her particular consequences would make one choice but the group as a whole faced with the consequences of a group decision would make the opposite choice. As a metaphor, Hardin refers to such choice 
situations as "the tragedy of the commons." Cook (1985, Chapter 12) discusses this problem from the perspective of energy policy and criticizes the assumption of laissez-faire economic theory that "the s:m of a vast number of selfish acts will, by the action of a benevolent invisible hand, turn out to be a social good .. . [page 354]." More recently, Waring (1989) discusses the reluctance of many economists to value outcomes that are not traded in the marketplace. "Economists say that the market prices (of, for example, medical treatment) reflect actual wants. But this gets very convoluted. If our actual wants are for clean air, fresh water and standing forests, we cannot possible express such desires, for they cannot be expressed in the market. No one and nothing records the permanent damage to water, air and ecosystems as an income accounting cost. [page 156]"

Second, there is the issue of whether a publin policy evaluation that depends on the estimation of a very uncertain quantity such as the indirect benefit of energy conservation-whose true but unknown size could be any amount from zero to infinity - should estimate the quantity to be zero on the ground that this procedure is the only "defensible" and "objective" approach or whether it should recognize the uncertainty involved and estimate the quantity as well as possible with the resources available to the evaluation.

On this issue, we believe that the method of estimating an important but uncertain quantity as zero is usually inappropriate. With a difficult estimation problem such as that of estimating the indirect costs of energy usage, it may be beyond the resources of a public policy study such as this one to provide an estimate that would be widely regarded as satisfactory. Then, it seems preferable to provide the reader with a description of the causes of the uncertain quantity (here, the types of social effects of energy usage) and to provide an indication of the range and probability distribution of the quantity (here, the sum of the social costs due to different types of effects of energy usage). In this report, a list of the social effects of energy usage is given in Table 4.1 below and a range for the total indirect cost is discussed.

The problem of estimating the indirect social costs of energy usage is in fact two estimation problems, both of them quite difficult. The first problem is that of identifying the various social effects of energy usage and for each type estimating the magnitude of the effect per unit of energy used. Much has been written on the identification and description of these social effects and on the estimation of their magnitudes. The table below provides a partial listing of identified social effects. This list is collected from many sources. 
Table 4.1. The social effects of conventional energy productior and usage

(1) Effects of air pollution on people

(2) Effects of air pollution on plants and animals

(3) Effects of air pollution on materials

(4) Effects of climatic changes

(5) Effects of routine operation of nuclear reactors

(6) Effects of meltdown accidents of nuclear reactors

(7) Effects of the transportation and storage of radioactive wastes

(8) Effects on national energy independence

(9) Effects concerning the subsidized-and thus indirect-monetary costs for energy

(10) Effects on military costs to protect Persian Gulf energy sources

(11) Effects of sabotage of energy installations or the theft of plutonium

(12) Effects on incentives for advances in energy conservation technology

This table does not provide any estimates of the magnitudes of the effects listed. Most of these magnitudes are made larger, and their estimation is made more difficult, because-unlike the direct costs for energy - they extend from the time when the energy is produced and used into the indefinite future. In this senst, they are cumulative over time. For example, an increase in the amount of spent nuclear fuel produced during a specified year adds to the problem of exposure to radioactive material both at that time and at later times.

The second problem for estimating the indirect costs of energy usage is that of assessing the costs to society per unit of magnitude for each effect of energy usage such as those listed above. These costs to society are of two types. First, there are monetary costs to members of society. For example, in (1) there is the lost income due to decreases in labor productivity and the monetary costs due to illnesses and deaths, in (2) there are the increases in costs for agricultural and forestry products, in (3) there are the increases in the costs of cleaning and maintaining buildings, and so forth. Second, there are non-monetary costs to members of society. For example, there are decreases in the quality of people's lives associated with environmental degradation, there is suffering and death associated with air pollution and radiation from nuclear material, and so forth.

The monetary costs can be estimated to a greater or lesser degree of accuracy by traditional methods of economic analysis. Such as estimation project is undertaken in the report of Hohmeyer (1988) that is discussed below. As is well known, the non-monetary costs are more difficult to 
estimate. The appropriate approach is to inquire as to the amounts of money that people would be willing to pay for a precisely and understandably specified improvement in a social effect of energy usage —often called a "contingent" improvement because it is proposed as a hypothetical choice rather than as an actual choice. Recently (that is, during the past decade or two), a methodology has been developed for gathering this type of information and modeling these types of value tradeoffs. The methodology is called the contingent valuation method. General discussions are in Bentkover, Covello, and Mumpower (1986) and in Cummings, Brookshire, and Schulze (1986). The method has been applied to the evaluation of a variety of environmental and non-environmental social benefits.

In this report, we will use the estimates of the indirect costs of energy that Hohmeyer (1988) has compiled and calculated in his study titled Social Costs of Energy Consumption. For the most part, Hohmeyer considers only the indirect monetary costs of energy. He measures in 1982 West German marks the indirect costs of the electricity that was generated in West Germany in $1984 \longrightarrow$ of which $75 \%$ was produced from fossil fuels and $25 \%$ was produced from nuclear power. His estimates are shown in Table 4.2 below.

Table 4.2. Indirect and direct costs of electricity production in West Germany (in $\mathrm{DM}_{82} / \mathrm{kWh}$ )

Indirect costs of electricity from fossil fuels $0.04-0.09$

Indirect costs of electricity from nuclear power

$0.10-0.21$

Average indirect costs of electricity

$0.05-0.12$

Average direct costs of electricity

$0.10-0.10$

The above estimates of indirect costs of electricity are minimal for several reasons. First, Hohmeyer excludes essentially all of the non-monetary indirect costs. "The major effecis which could not be quantified and monetarized in the study are:

- the psycho-social costs of serious illnesses or deaths as well as the costs to the health care system - the environmental effects of the production of intermediate goods used for investments in energy systems and the operation of these systems - the environmental effects of all stages of the fuel cycles (specifically in the case of nuclear energy) - the full cost of climatic changes

-- the environmental risks of routine operation of nuclear power plants - hidden subsidies for energy systems given under other titles. [page 96]" 
The second reason that the indirect costs in Table 4.2 are minimal is that Hohmeyer is careful in each of his estimates of a monetary indirect cost to estimate only those costs that can be clearly identified and monetarized. He states: "All figures given are oriented towards the probable minimal external effects of any of the systems studied. [page 29]" For example, Hohmeyer estimates a total public subsidy for electricity generation of $0.009 \mathrm{DM}_{82} / \mathrm{kWh}$ which he believes "is most likely a vast underestimation. The costs of most public services not covered by fees are extremely difficult to approximate and could not be included. [page 95]"

Based on this reasoning, we will use the upper estimate of $0.12 \mathrm{DM}_{82} / \mathrm{kW}$ I as the estimate of the monetary indirect costs of electricity generation in West Germany in 1984. Moreover, we estimate the non-monetary indirect costs to be as great as the monetary indirect costs-we conje"ture that indeed they are much greater so that we are underestimating the non-monetary costs. (In future studies, the non-monetary costs should be estimated by the contingent valuation method discussed above.) In conclusion, we estimate the sum of the monetary and non-monetary indirect costs of electricity to be $0.24 \mathrm{DM}_{82} / \mathrm{kWh}$.

We suppose that the ratio of indirect costs to direct costs is approximately the same in West Germany as in the United States, approximately the same in 1984 as in 1985, and approximately the same for electricity generation as for the average of all types of energy usage in residential housing. Thus, we estimate that at present the indirect costs of energy usage are approximately $0.24 / 0.10=2.4$ times the direct costs of energy usage.

As discused in Section 2, the direct costs of energy usage per building unit are estimated to increase at a rate of $3.4 \%$ per year. At what rate should the indirect costs be estimated to change? We see no reason why the rate should be the same as that for the direct costs. We do, however, see several reasons for a positive rate, i.e., for a gradual escalation in the social costs of energy usage. First, many of the indirect effects of energy usage listed in Table 4.1 are cumulative over time or will increase faster than in direct proportion to the energy usage. Second, social values regarding these indirect effects may continue to change so that society's willingness to pay in order to reduce such effects continues to increase. Present society may wish to consider these values of people who will be living in future times.

In this report, however, we use an escalation rate of $0 \%$ for the indirect costs of energy usage. We believe that because of this modeling choice, we are almost certainly underestimating the social benefits of reductions in energy usage. With this model, the ratio of indirect costs to direct costs decreases from 2.4:1 at the present, $t=1$, to much smaller ratios at future times, for example, to a ratio of about $1: 1$ at time $t=25$ and to a ratio of less than $0.1: 1$ at time $t=10()$. 
We also need to estimate the indirect effects of adciilional construction in federal residential buildings that will result from the proposed energy consevation standard. If, for example, asbestos insulation were to be used, then these indirect effects would be significant. However, there do not appear to be any effects of this type with the use of current materials and methods. Thus, we estimate the indirect effects of additional construction to be zero.

In summary, when we include the indirect costs of energy usage in the analysis, then the benefits of energy savings, that is, each FCD reported in Tables 2.2 and 3.1, is changed to a FCD that is greater than the FCD reported there. These increased FCD benefits are provided in the following table.

Table 4.3. Inclusion of indirect costs in the estimation of the benefits of energy savings

\begin{tabular}{lccc} 
& $\begin{array}{c}\text { Present value discounting } \\
\text { with a rate of } 7 \%\end{array}$ & \multicolumn{2}{c}{ Relative value discounting with } \\
& $\$ 10,145$ & $\$ 25,751$ & $\mathrm{i}=.05, \mathrm{~m}=20$ \\
The benefit $(\mathrm{FCD})$ & $-\$ 1,329$ & $-\$ 1,622$ & $\$ 32,289$ \\
The cost (NFCD) & $\$ 8,816$ & $\$ 24,129$ & $-\$ 1,750$ \\
The benefit-cost difference & 7.63 & 15.88 & $\$ 30,539$ \\
The benefit-cost ratio & &
\end{tabular}

The inclusion and the estimation of the social benefits of energy savings leads in this section to benefit-cost ratios that are far greater than the ratios that are calculated from the EASIECS report in Sextion 1 or that are estimated in Sections 2 and 3. We recommend that a study of an ene:gy conservation proposal should describe all the important effects of the proposal including the energy costs that occur not for the individual who uses the energy but for all members of society. If sufficiently large, these indirect costs can justify the introduction of government requirements concerning the conservation of energy. For this reason, we believe that the benefit-cost ratios in Table 4.3 are more appropriate than the benefit-cost ratios reported in the previous sections for an evaluation of the proposal for energy conservation being considered in this report.

\section{The Benefit-Cost Ratio as a Criterion for Public Policy Evaluation}

How should the benefits and costs of a proposed public policy be combined to measure the attractiveness of the policy? Cost-benefit theory recommends as a general principle that the policy 
should be evaluated by considering the benefits minus the costs, that is, the net benefits discounted for the times at which they occur. Stokey and Zeckhauser (1978) explain this idea as follows:

"Let's suppose for the moment that we have already determined the benefits and costs, and hence the net benefits, of several proposed projects. How do we choose among them? In other words, what should the decision rule be ? All benefit-cost analyses hinge on the Fundamental Rule:

In any choice situation, select the alternative the produces the greatest net benefit. [page 137]"

In this section, we will point out several of the difficulties in applying this rule and argue as to how the rule shculd be applied in the evaluation of the energy conservation standard.

The first difficulty is that often the alternative projects are not identified. Then, there is no basis for specifying a common range of the effects of the alternatives. The EASIECS report specifies the range as the effects on the estimated 18,500 building units to be constructed during a five year period. The average benefits and costs per building unit are multiplied by 18,500 to calculate a net benefit of $\$ 27$ million in 1985 dollars. As noted in Section 1, the EASIECS report concludes that "This net figure of $\$ 27$ million, if it was an accurate estimate of the annual effect, would be too small at the national level to be significant. [page 3.8]" There is no discussion in the EASIECS report that identifies alternative projects and explains in terms of these projects why the range of a five year period was chosen or why a net benefit of $\$ 27$ million was judged to imply that the energy proposal is not worthwhile. The EASIECS report appears to suggest that if the number of affected building units were substantially increased, then the net benefit would become sufficiently large so that the energy proposal would be worthwhile. It does not discuss, however, how many affected building would be needed or why the proposal would be worthwhile for a large number of building units bui not for a small number of units.

A second difficulty in applying the above rule is that often there is a budgetary constraint on the initial cost. In such a situation, if the proposed project is one in a list of mutually exclusive projects whose costs and benefits are measured according to a common range, then the optimal project is that which has the greatest net benefit among those projects which meet the budgetary constraint. This criterion can be difficult to apply, however, if the budgetary limit is not clearly specified.

A third difficulty in applying the above rule is that often the projects to be selected are not mutually exclusive. Then, the "alternatives" that should be judged by their net benefits are sets of projects rather than single projects. In the absence of constraints, this distinction is unimportant- 
one chooses the set of those projects having positive net benefits. When there are budgetary ccnstraints, however, some projects with positive net benefits may have to be set aside in order to stay within the budgetary limit.

For the decision problem of evaluating the proposed energy conservation standard, we believe that the three difficulties described above are best addressed by means of the following assumptions:

(a) The proposed energy standard is one in an unspecified list of public projects. Moreover, the sizes of these projects can be changed thereby changing their costs and benefits.

(b) There are budgetary constraints on the initial costs (e.g., the extra construction) that can be aliocated to the projects in the list. However, these budgetary constraints are not specified.

(c) The projects are not mutually exclusive, i.e., if budgetary constraints are ignored, then any number of these projects could be undertaken.

A decision problem of type (a)-(c) usually is referred to as a capital rationing problem or as an input rationing problem. It is a well known result of cost-benefit theory that for such a problem the projects to be selected are those with the highest ratio of henefits to initial costs. When the benefits are all in the future, it will not affect the selection of projects whether one considers the ratio of future net benefits to initial costs or the ratio of total net benefits to initial costs since these two ratios differ by the constant 1 .

Sugden and Williams (1978) describe the situation as follows: "The agency's objective is to maximize its financial surplus, subject to the constraint imposed by the input limitation. Clearly it should undertake the set of projects whose total present value is greatest. This implies that it should undertake those projects with the highest present value per unit of the constrained input that they use. [page 76]"

Stokey and Zeckhauser (1978, pages 142-143) appeal to the same result when they observe that if there is a constraint on capital outlay funds, then projects should be chosen which have the highest net benefit to initial cost ratios. For a decision problem of this type, they interpret their Findamental Rule as recommending that one select the package of projects that satisfies the constraint on funds and maximizes the total net benefit.

This result of cost-benefit theory can be stated in mathematical terms as follows. Consider an agency that wishes to select a set of projects from a list of $n$ projects so as to maximize its overall net benefit from the projects. Suppose the $j$-th project has an initial cost of aj dollars and a net benefit of $b_{j}$ dollars for $j=1, \ldots, n$. Suppose there is a budget of $C$ dollars for initial costs, 
and that if a project is scaled down to a fraction of its largest size, then the initial costs and the net benefit are scaled down proportionally. Let $x_{j}, j=1, \ldots, n$, denote the fraction of the $j$-th project undertaken. Then, we have the following linear programming model:

$$
\begin{aligned}
\operatorname{rnaximize} & z=\sum_{j} b_{j} x_{j} \text { subject to } \\
& \sum_{j} a_{j} x_{j}=C \\
0 \leq x_{j} & \leq 1, j=1, \ldots, n
\end{aligned}
$$

Theorem. If in the linear programming model $(8)$ the projects, $j=1, \ldots, n$, are labeled so that

$$
b_{1} / a_{1}>b_{2} / a_{2}>\ldots .>b_{n} / a_{n}
$$

then the optimal solution is

$$
x_{1}=1, \ldots, x_{k-1}=1, x_{k}=\left(C-a_{1}-\ldots-a_{k-1}\right) / a_{k}, x_{k+1}=0, \ldots, x_{n}=0
$$

where $k$ is the least integer such that $a_{1}+\ldots+a_{k} \geq C$.

Proof. This optimization problem in discussed in Dantzig (1963). Rattier than giving a proof, Dantzig states that "because of its very simple form, it admits an immediate solution: .. I page 518]" The following proof is based on a well-known argument (see, e.g., Harvey, 1979, pages 221- 225) and is the most "immediate" proof that we can devise.

Suppose that $y_{1}, \ldots, y_{n}$ is any solution of (8) other than the solution (9). We will show' that $y_{1}, \ldots, y_{n}$ is non-optimal. Note that $y_{j}<1$ for some $j<k$ or $y_{j}>0$ for some $j>k$. In the first case, find an amount $y_{j}<1, j<k$, and an amount $y_{j}{ }^{\prime}>0, j^{\prime} \geq k$. Then, increase $y_{j}$ so that $a_{j} y_{j}$ is increased by an amount $\Delta$, and decrease $y_{j}$ so that $a_{j} y_{j}$ is decreased by the same amount $\Delta$. These changes will preserve the constraints and will increase the overall net benefit $z$ by the amount $\left(b_{j} / a_{j}-b_{j^{\prime}} / a_{j}{ }^{\prime}\right) \Delta$. Thus, the solution $y_{1}, \ldots, y_{n}$ is non-optimal. If the solution $y_{1}, \ldots, y_{n}$ is in the second case, then a similar argument can be given.

We believe that the assumptions (a)-(c) stated above are reasonably well satisfied for the proposed energy conservation standard and that therefore the above result is applicable. Thus, we recommend that the standard be judged by its ratio of future net benefits to initial costs. 
We have not, however, been scrupulous to adhere to our own advice. Instead of considering the ratio of future net benefits to initial costs, we have considered the ratio of energy savings (the fuel cost difference, FCD) to non-fuel costs (the non-fuel cost difference, NFCD). The reason is that it seems useful to distinguish between the energy effects and the non-energy effects of the proposed standard, namely, its expected energy savings and its expected non-energy costs.

For the most part, the future effects are synonymous with the energy savings, and the present effects are synonymous with the non-energy costs. The exceptions are the non-fuel costs of maintenance that occur in the future. These costs are included in the formula (5) for the non-fuel cost difference. If they are transferred to the formula (4) for the fuel cost difference, then we have the following division between future net benefits (FNB) and initial costs (IC).

$$
\begin{aligned}
F N B= & \left.\Sigma_{i}\left[\sum_{t} a_{t} s_{t} e_{i}(t)\right] / 140-\left(a_{15} s_{15}+a_{30} s_{30}+\ldots\right) \Sigma_{i} c_{i}(15) / 140\right) \\
& -\left(a_{18} s_{18}+a_{36} s_{36}+\ldots\right) \Sigma_{i} c_{i}(18) / 140 \\
I C= & \Sigma_{i} c_{i} / 140
\end{aligned}
$$

The ratio of future net benefits to initial costs, FNB/IC, can be calculated by means of formulas (10) and (11) for each of the assumptions on social value considered in this report. These benefit-cost ratios are shown in the table below.

Table 5.1. Ratios of fuel savings to non-fuel costs, FCD/NFCD, and ratios of future net benefits to initial costs, FNB/IC

FCD/NFCD $\quad$ FNB/IC

(a) Social energy costs excluded

PV discounting with $\mathrm{i}=0.07$

RV discounting with $\mathrm{i}=0.07, \mathrm{~m}=15$

$R V$ discounting with $\mathrm{i}=0.05, \mathrm{~m}=20$

(b) Social energy costs included

PV discounting with $i=0.07$

RV discounting with $\mathrm{i}=0.07, \mathrm{~m}=15$

$\mathrm{RV}$ discounting with $\mathrm{i}=0.05, \mathrm{~m}=20$ 
The purpose of any decision analysis study is to provide insight for decision making rather than to calculate an optimal decision. This decision analysis report follows that general pattern. In particular, there are two questions that are intended to be clarified but not judged in this report.

First, there is the question of how large a benefit-cost ratio is needed for the proposed energy standard in order to render it preferable to not adopting the standard. As discussed in this section, a response to this question depends on the size of the budget for initial costs and on the benefit-cost ratios for alternative projects. Both of these matters must be judged-either directly or indirectlyby those persons responsible for deciding whether to adopt the standard.

Second, there is the question of what social values should be used in making the tradeoffs between the various effects of the proposed standard. Section 3 and 4 discuss and model a variety of these social values. Again, the matter must be judged-either directly or indirectly-by those persons responsible for deciding whether to adopt the standard.

We have presented in this report several suggestions that are intended to aid insight into an evaluation of the proposed energy conservation standard for new federal residential housing. The methods we have used for modeling issues of public values may be controversial as they' differ from those typically used in cost-benefit studies. W'e would encourage discussion and suggestions from other interested persons regarding these methods. We feel that the methods used in this report warrant further examination as a potential addition to the repertory of methods that are used in energy policy studies. 


\section{References}

Bentkover, J.D., V.T. Covello, and J. Mumpower (eds.). Benefits Assessment: The State of the Art. D. Reidel, Dordrecht, Holland (1986).

Benzion, U., A. Rapoport, and J. Yagil, "Discount Rates Inferred from Decisions: An Experimental Study," Management Science, 35 (1989), 270-284.

Cook. E. Man, Energy, Society. W.H. Freeman, San Francisco (1976).

Cummings, R.G., D.S. Brookshire, and W.D. Schulze (eds.). An Assessment of the Contingent Valuation Method. Rowman and Allanheld, Totowa, New Jersey (1986).

Dantzig, G. Linear Programming and Extensions. Princeton University Press, Princeton (1963).

Fischhoff, B., S. Lichtenstein, P. Slovic, S.L. Derby, and R. Keeney. Acceptable Risk.

Cambridge University Press, Cambridge (1981).

Harvey, C.M. Operations Research: An Introduction to Linear Optimization and Decision Analysis. North-Holland, New York (1979).

Harvey, C.M., "Value Functions for Infinite-Period Planning," Management Science, 32 (1986), 1123-1139.

Harvey, C.M., "Utility Functions for Infinite-Period Planning," Management Science, 34 (1988), 645-665.

Hardin, G., "The Tragedy of the Commons," Science, 162 (1968), 1243-1248.

Hchmeyer, O. Social costs of Energy Consumption. Springer-Verlag, Berlin (1988).

Horowitz, J.K., "Discounting Money Payoffs: An Experimental Analysis," Working Paper,

Department of Agricultural and Resource Economics, University of Maryland (1988).

Koopmans, T.C., "Stationary Ordinal Utility and Impatience," Econometrica, 28 (1960), 287-309.

Lind, R.C., K.A. Arrow, G.R. Corey, P. Dasgupta, A.K. Sen, T. Stauffer, J.E. Stiglitz, J.A.

Stockfisch, and R. Wilson. Discounting for Time and Risk in Energy Policy. Resources for the Future, Inc., Washington, D.C. (1982).

Loewenstein, G. and D. Prelec, "Anomalies in Intertemporal Choice: Evidence and an Interpretation," Working Paper, University of Chicago Center for Decision Research (1989).

Lovins, A.B., "Cost-Risk-Benefits Assessments in Energy Policy," George Wasinington Law Review, 45 (1977), 911-943.

Manne, A.S. and L. Schrattenholzer. International Energy Workshop: Overview of Poll Responses. Stanford University. Janliary, 1990. 
Mlishan, E.J. Cost-Benefit Analysis. Praeger Publishers, New York, (1976).

Mishan, E.J. Introduction to Normative Economics. Ox rord University Press, New York (1981).

Mitnick, P., A. Tuluca, R. Boschen, A.D. Lee, J.A. Heidell, and R.G. Pratt. Draft Conservation Optimization Standard for Savings in Federal Residences (COSTSAFR)-User's Manuel. Pacific Northwest Laboratory, Richland, Washington (1985).

Stokey, E. and R. Zeckhauser. A Primer for Policy Analysis. W.W. Norton, New York (1978).

Sugden, R. and A. Williams. The Principles of Practical Cost-Benefit Analysis. Oxford University Press, Oxford (1978).

Thaler, R., "Some Empirical Evidence of Dynamic Inconsistency," Economics Letters, 8 (1981) 201-207.

U.S. Census Bureau. 1979 Annıal Housing Survey (Part A: General Housing Characteristics).

U.S. Department of Energy Memorandum. Office of Policy Planning and Analysis. Office of Technology Policy. Richard Holt, February 27, 1989.

U.S. Department of Energy. Technical Support Document. In Support of Interim Energy Conservation Standards for New Federai Residentia! Buildings. Vol. 2 of 4. DOE/CE0223. Office of Buildings and Community Systems. June, 1988.

U.S. Department of Energy. Economic Analysis. In Support of Interim Energy Conservation Standards for New Federal Residential Buildings. Vol. 4 of 4. DOE/CE-0223. Office of Buildings and Community Systems. June, 1988.

Waring, M. If Women Counted: A New Feminist Economics. Harper and Row, San Francisco (1989). 


\section{Appendix A: Calculation of the Spreadsheet Information Used in this Report}

The HEATDATA sprearsheet presents data on 140 building configurations. Calculations are performed to determine the yearly capital costs and yearly snergy savings. A printout of the spreadsheet is attached.

(A) Location

Region examined in data to the right.

(B) Prototype

Building type examined in the data to the right.

(C) Fuel

Heating fuel type examined in the data to the right. OIL is fuel oil, GAS is natural gas, LPG is liquified propane gas, ELEC is electricity, and HP is heat pump which is driven by electricity.

(D) NUM

An identifying number assigned to each location, prototype, and fuel type building combination.

\section{(E) LCC HEATING}

Difference in Life Cycle heating costs from Attachment C, Table 1 of correspondence with Pacific Northwest Laboratories, July 26, 1989. Difference in Life Cycı heating costs is the difference in yearly heating fuel expenditures between standard and common designs (standard minus common) discounted at 7\%. Note that the sum of columns (E) and (F) equals the DIFFERENCE FUEL LCC column in Tables A.1-A.4, Pages A.2-A.5 in the EASIECS report.

(F) L.CC COOLING

Difference in Life Cycle cooling costs from Attachment C, Table 1 of correspondence with Pacific Northwest Laboratories, July 26, 1989. Difference in Life Cycle cooling costs is the difference in yearly cooling fuel expenditures between standard and common designs discounted at $7 \%$.

(G) HEAT UPWF

Uniform present worth factors from Attachment $D$ of correspondence with Pacific Northwest Laboratories, July 26,1989 . The uniform present worth factors are used to convert the LCC 
HEATING numbers, discounted present value of differences in heating fuel savings, to yearly fuel consumption (see notes on HEAT CHANGE, column $\mathrm{K}$ ). The factors consider both the fuel price escalation rates and the $7 \%$ discount rate.

(H) COOL UPWF

Uniform present worth factors from Attachment D of correspondence with Pacific Northwest Laboratories, July 26, 1989. The uniform present worth factors are used to convert the LCC COOLING numbers, discounted present value of differences in cooling fuel savings or electricity, to yearly fuel consumption (see notes on COOL CHANGE, column L). The factors consider both the fuel price escalation rates and the $7 \%$ discount rate.

\section{(I) HEAT COST}

FEMP average fuel prices from Table A.12, Page A.12 of the EASIECS report.

\section{(J) COOL COST}

FEMP average fuel prices from Table A.12, Page A.12 of the EASIECS report.

(K) HEAT CHANGE

The difference in heating fuel use between standard and common buildings. Units for column (L) are kwhr for ELEC and HP, therm for GAS, gal for LPG, and gal for OIL. To determine the difference in fuel use, the LCC HEATING (E) is divided by HEAT UPWF (G) times HEAT $\operatorname{COST}(\mathrm{I})$ or $(\mathrm{E}) /[(\mathrm{G}) \times(\mathrm{I})]$. The formula is from correspondence with Pacific Northwest Laboratories, July 26, 1989.

\section{(L) COOL CHANGE}

The difference in cooling fuel (electricity) use between standard and common buildings. Units for column (L) are kwhr for all entries. To determine the difference in fuel use, the LCC COOLING $(F)$ is divided by COOL UPWF $(H)$ times COOL COST $(J)$ or $(F) /[(H) x(J)]$. The formula is from correspondence with Pacific Northwest Laboratories, July 26, 1989.

\section{(M) LCC OTHER}

LCC OTHER are the differences in life cycle costs between standard and common buildings due to non-fuel expenditures. These include initial expenditures, replacement costs, and salvage costs. The column is directly from the DIFFERENCE OTHER LCC column in Tables A.1 through A.4, Pages A. 2 through A.5 in the EASIECS report. 
(N) AC 15 YR

The difference in air conditioning replacement costs between standard and common buildings in year 15. All common buildings are assumed to have cooling SEER of 7.0 from correspondence with Pacific Northwest Laboratories, July 26, 1989. The cooling SEER for each standard building's air conditioner is from Table C.2, Pages C.5-C.8 of the EASIECS report. (Note that labels on Tables C.1 and C. 2 are reversed. C. 1 refers to actual prices and C. 2 refers to FEMP prices.) The differences in replacement costs are from Table 3.27, Page 3.50 of the Technical Support Document: In support of Interim Energy Conservation Standards for New Federal Residential Buildings (June 1988). Heat pumps use single units for heating and cooling; therefore 0.00 appears for all heat pump entries in column $(\mathrm{N})$.

(O) HEAT 15 YR

The difference in heating replacement costs between standard and common buildings in year 15 . Only heating pump units are replaced in year 15. All common buildings are assumed to have heat pumps with HSPF values of 5.5 from correspondence with Pacific Northwest Laboratories, July 26, 1989. The HSPF for each standard building's heat pump is from Table C.2, Pages C.5-C.8 of the EASIECS report. (Note that labels on Tables C.1 and C.2 are reversed. C. 1 refers to actual prices and C.2 refers to FEMP prices.) The differences in replacement costs are from Table 3.25, Page 3.48 of the Technical Support Document: In support of Interim Energy Conservation Standards for New Federal Residential Buildings (June 1988).

(P) HEAT 18 YR

The difference in heating replacement costs between standard and common buildings in year 18 . Common buildings are assumed to have the following heating efficiencies OIL -0.75, GAS -0.65 , and LPG - 0.65 from correspondence with Pacific Northwest Laboratories, July 26, 1989. The heating efficiency for each standard building's heating is from Table C.2, Pages C.5-C.8 of the EASIECS report. (Note that labels on Tables C.1 and C.2 are reversed. C. 1 refers to actual prices and C.2 refers to FEMP prices.) The differences in replacement costs are from Tables 3.23 and 3.24, Pages 3.46 and 3.47 of the Technical Support Document: In support of Interim Energy Conservation Standards for New Federal Residential Buildings (June 1988).

(Q) AC 25 YR

The difference in air conditioning salvage values between standard and common buildings in 
year 25. All common buildings are assumed to have cooling SEER of 7.0 from correspondence with Pacific Northwest Laboratories, July 26, 1989. The cooling SEER for each standard building's air conditioner is from Table C.2, Pages C.5-C.8 of the EASIECS report. (Note that labels on Tables C.1 and C.2 are reversed. C.1 refers to actual prices and C.2 refers to FEMP prices.) The differences in replacement costs are from Table 3.27, Page 3.50 of the Technical Support Document: In support of Interim Energy Conservation Standards for New Federal Residential Buildings (June 1988). Heat pumps use single units for heating and cooling therefore 0.00 appears for all heat pump entries in column $(Q)$.

\section{(R) HEAT 25 YR}

The difference in heating salvage values between standard and common buildings in year 25 . Common buildings are assumed to have the following heating efficiencies OIL - (0.75, GAS - 0.65, LPG - 0.65, HP - 5.5 from correspondence with Pacific Northwest Laboratories, July 26, 1989. The heating efficiency for each standard building's heating is from Table C.2, Pages C.5-C.8 of the EASIECS report. (Note that labels on Tables C.1 and C.2 are reversed. C.1 refers to actual prices and C. 2 refers to FEMP prices.) The differences in replacement costs are from Tables 3.23, 3.24, and 3.25, Pages 3.46, 3.47, and 3.48 of the Technical Support Document: In support of Interim Energy Conservation Standards for New Federal Residential Buildings (June1988).

\section{(S) $1 \mathrm{ST}$ COST}

The difference in 1st year or construction capital costs for standard and common buildings. This cost is calculated by subtracting the discounted replacement costs, found in columns $(N),(O)$, $(P),(Q)$, and (R), from column (M). Using the " $\wedge$ " symbol to indicate exponentiation, the formula for $(\mathrm{S})$ is: $(\mathrm{M})-[(\mathrm{N})+(\mathrm{O})] /\left[1.07^{\wedge} 15\right]-(\mathrm{P}) /\left[1.07^{\wedge} 18\right]-[(\mathrm{Q})+(\mathrm{R})] /\left[1.07^{\wedge} 25\right]$. 


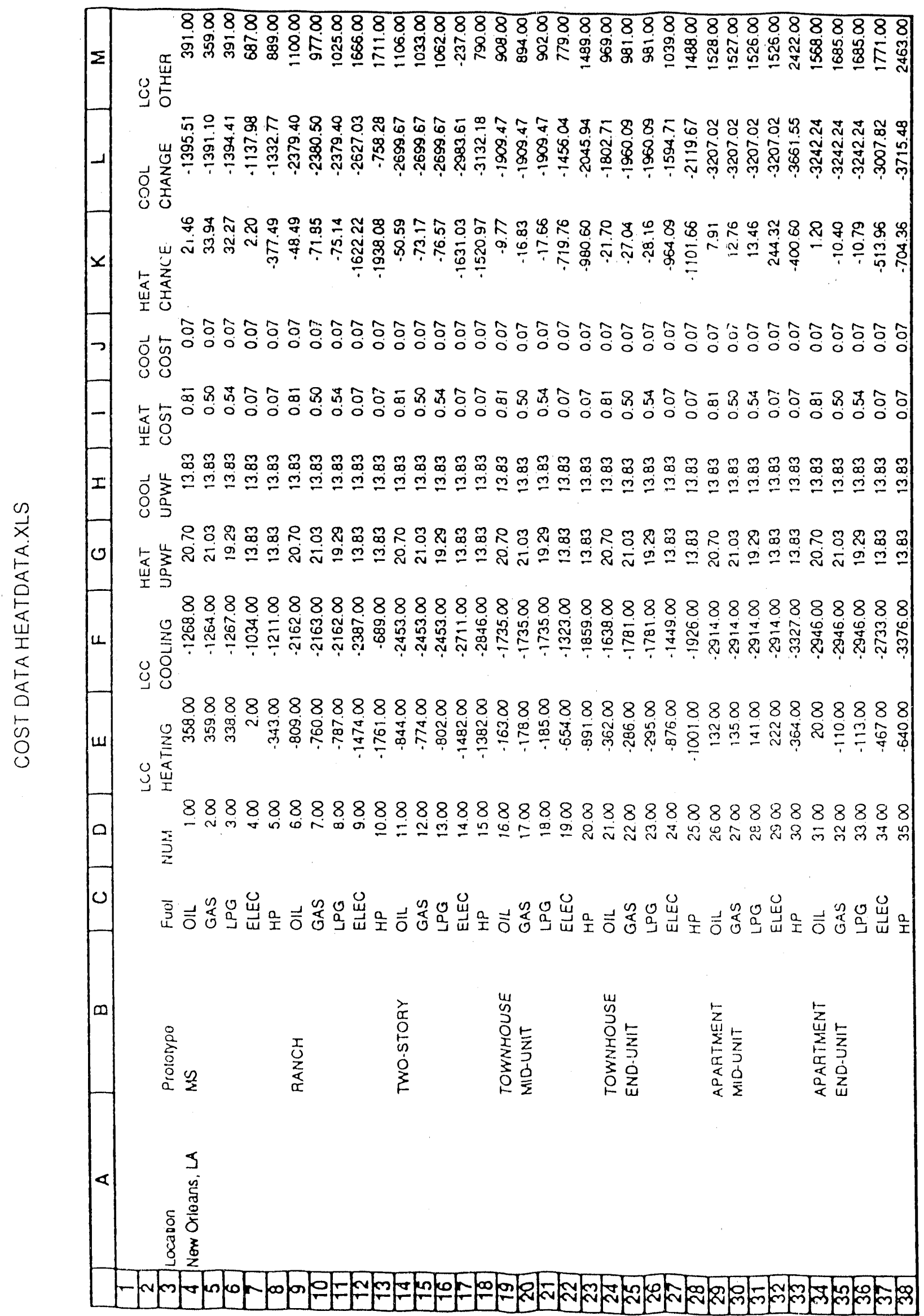




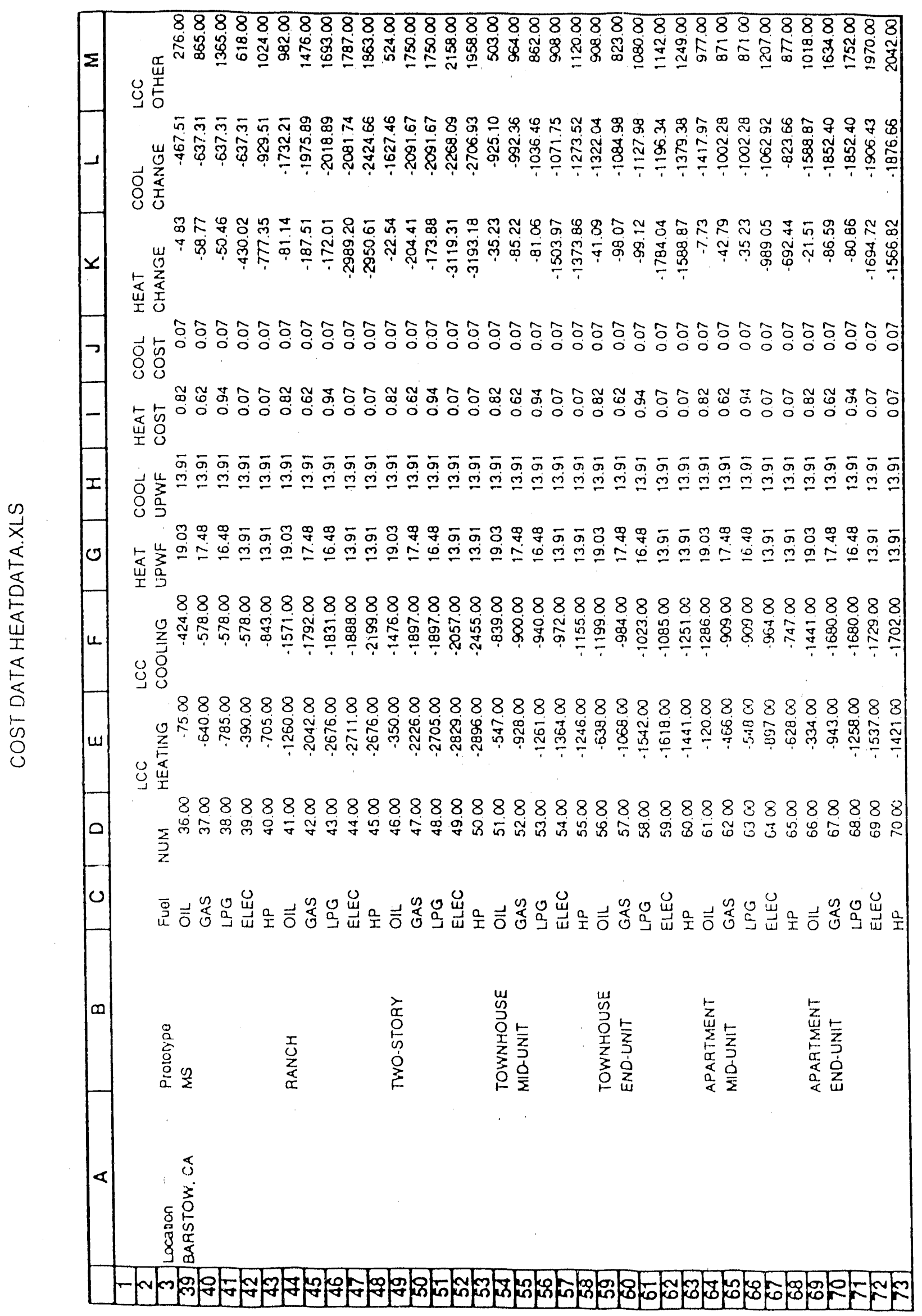




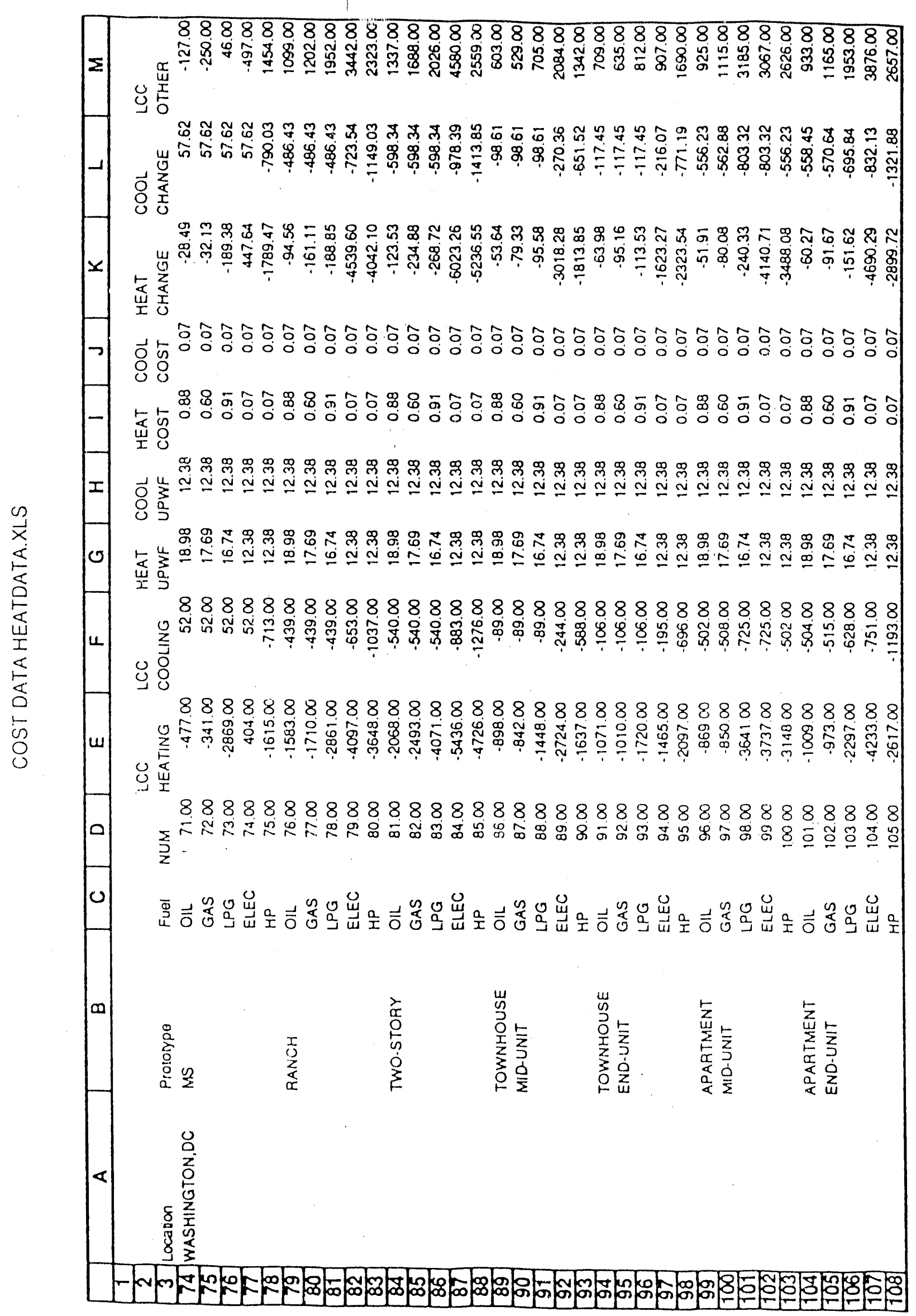




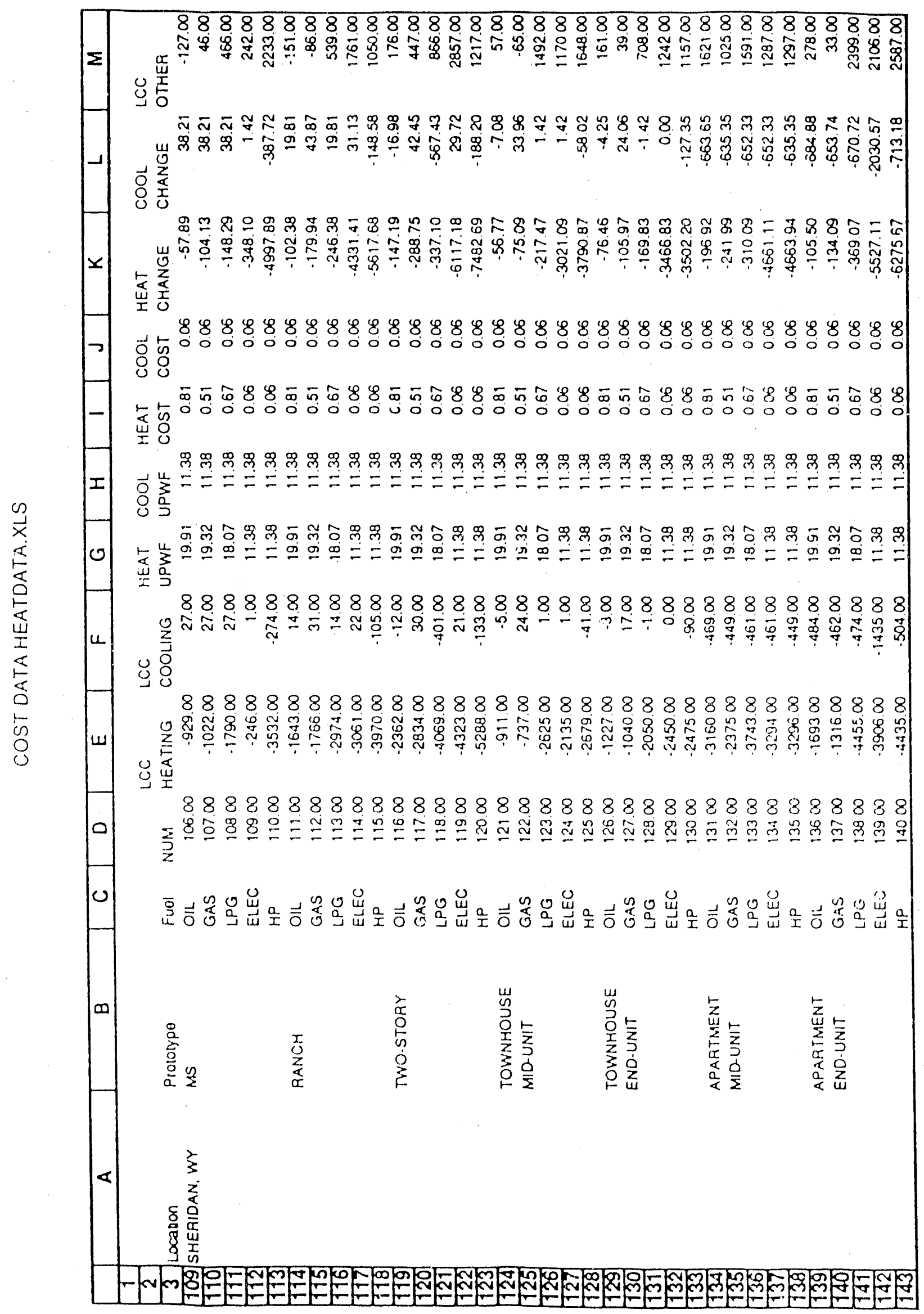




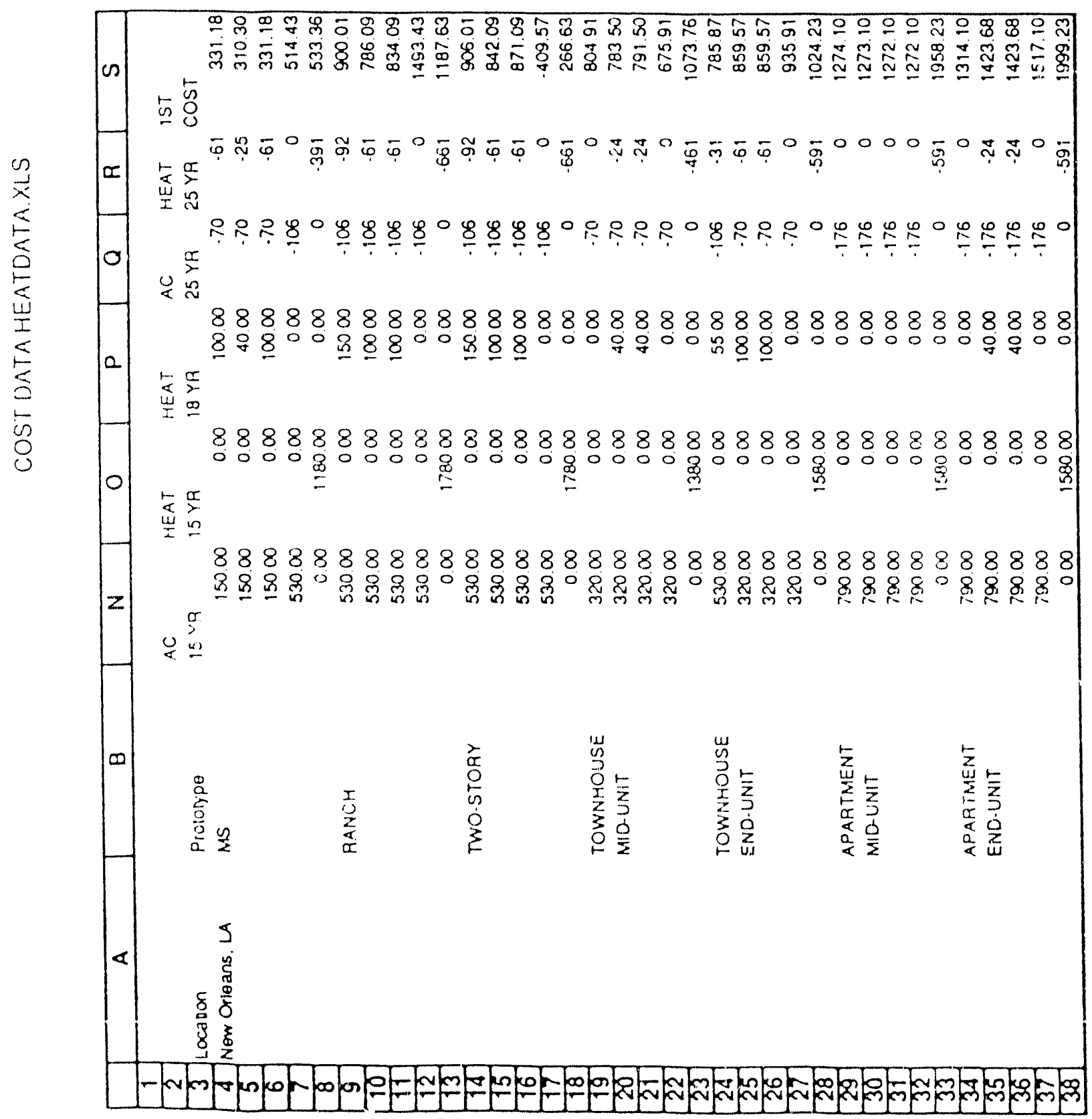




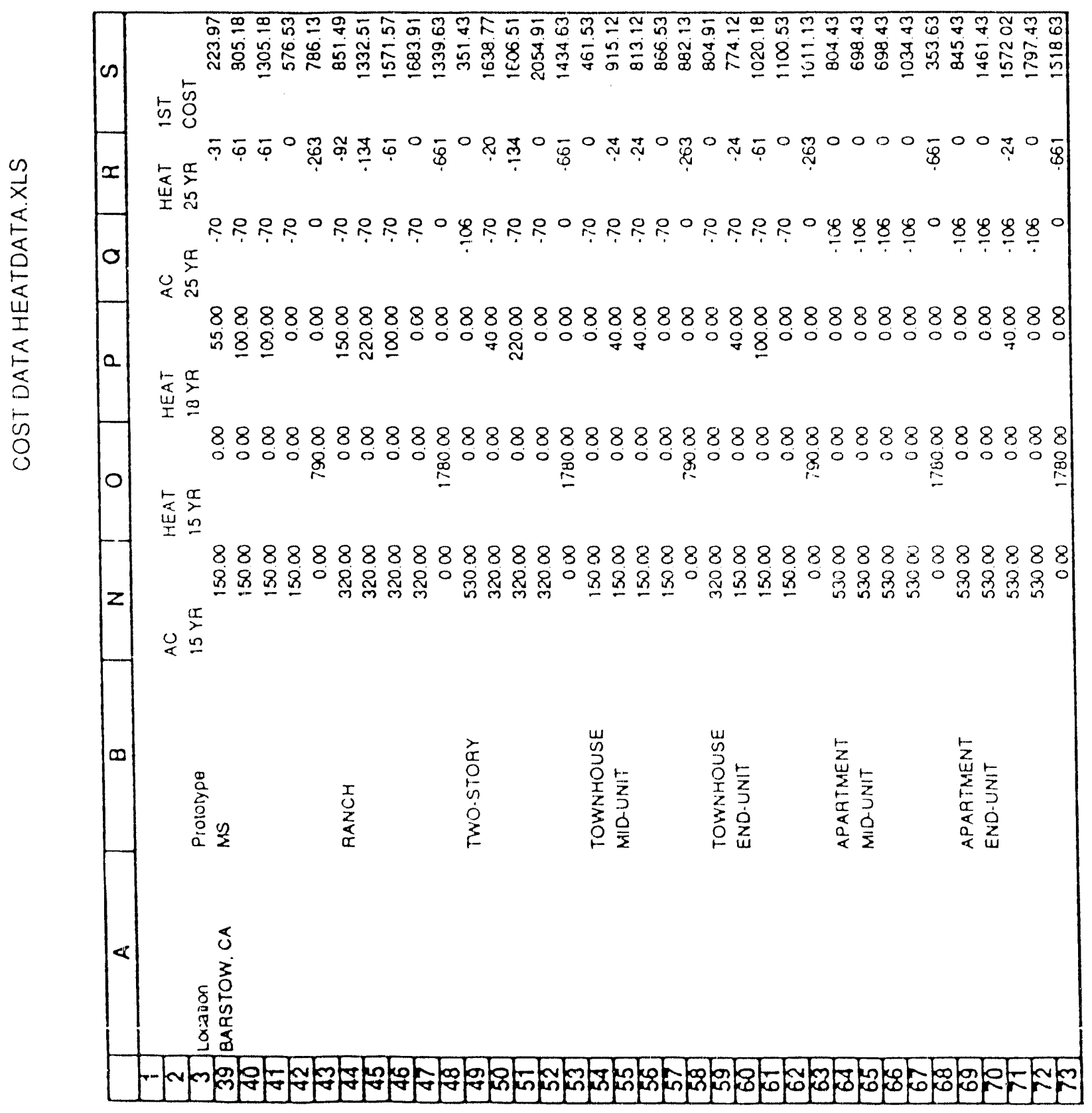




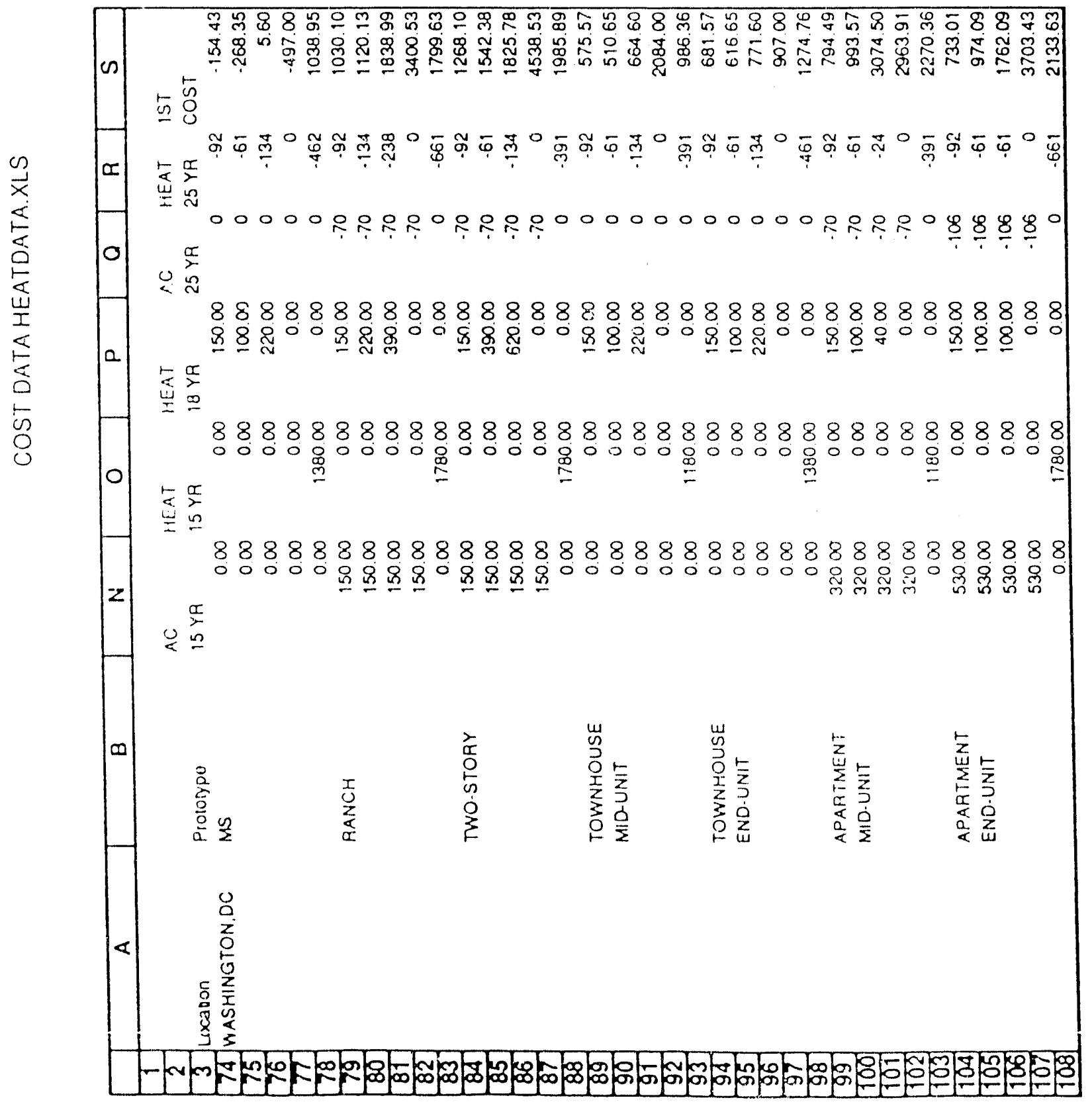




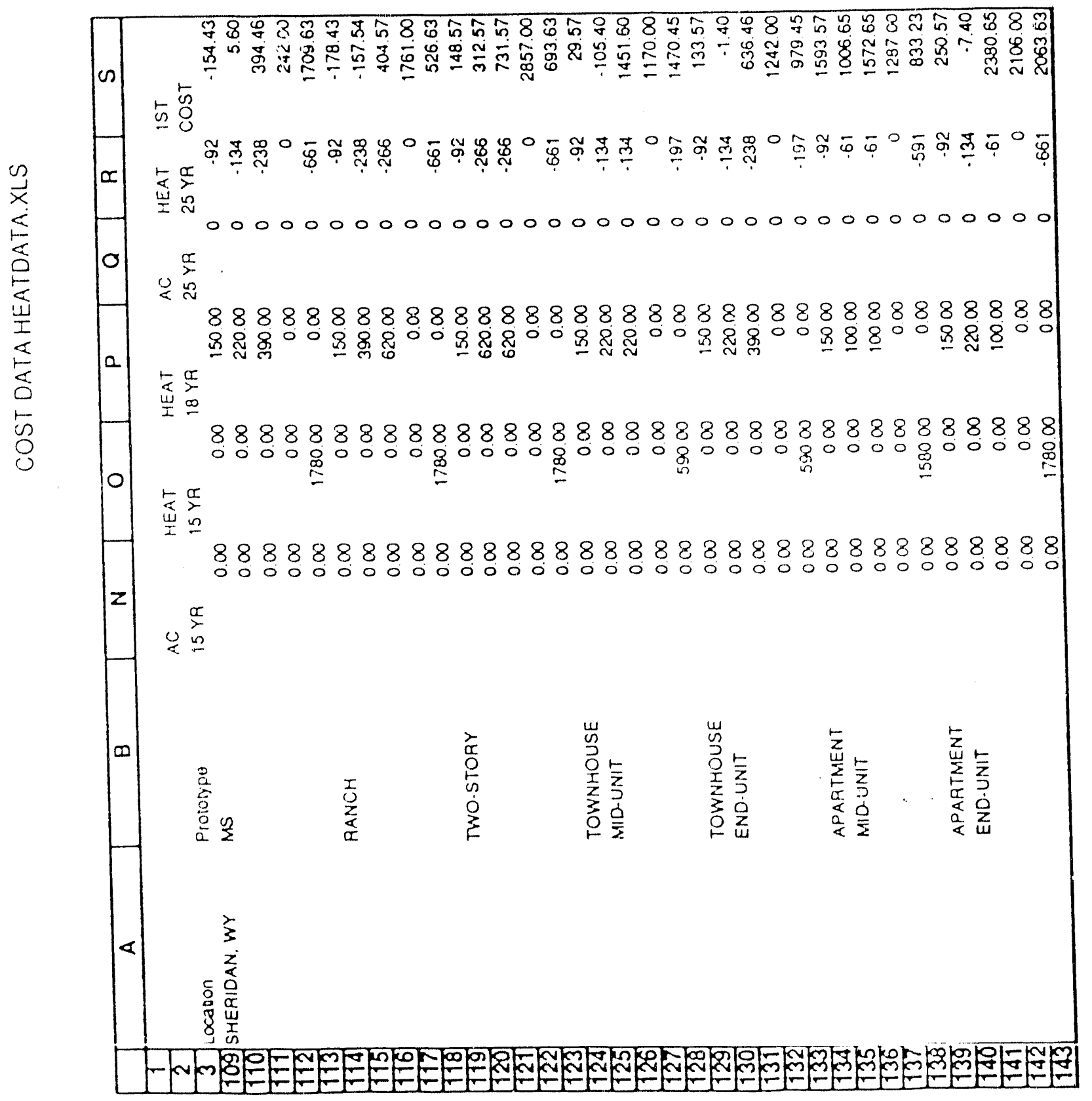




\section{Appendix B: Decision Analysis}

\section{B.I. Introduction}

One of the most difficult problems faced by public and private decision makers is how to make good decisions under uncertainty. Uncertainty introduces complexity to decision making, whether it concerns energy policy decisions, environmental regulation, or the profitability of a new product. Uncertainty raises both methodological and philosophical questions. How should choices be evaluated when the consequences are uncertain? When do we have enough information to make a decision? How much should we pay for new information that can reduce our uncertainty? What is the "right" level of risk?

Decision analysis is a philosophy and a method for answering questions like these. It provides a logical framework for decision making based on what you know, what you can do, and what you prefer. Decision analysis is based on the principles of probability theory and a set of normative axioms derived from utility theory. The principles and techniques of decision analysis have been successfully applied to a wide range of commercial and public policy problems.

The popularity of decision analysis owes mainly to its:

- Simple and intuitive nature

- Explicit consideration of uncertainty

- Usefulness as a communication tool

- Ability to incorporate into decision making both statistical data and the experience of experts.

An important benefit of decision analysis is that it provides a formal, unequivocal language for communication among the people in the decision making process. The basis for the decision becomes evident, not just the decision itself. By clarifying the basis for decisions, decision analysis highlights gaps in information and disagreements about the interpretation of information. Revealing such problems is an essential first step in their resolution.

\section{B.2. Overview of Decision Analysis}

This section briefly reviews the major features of typical decision analysis problems and a process for conducting decision analysis. For a more detailed description of the underlying concepts of decision analysis, see Howard and Matheson (1981) or Raiffa (1968). 


\section{Appropriate Problems for Decision Analysis Applications}

Decision analysis problems typically share two major features. They have a large number of interrelated and uncertain variables and a decision process that links each decision with what is known about these variables at the time each decision is made.

\section{The Decision Analysis Process}

The decision analysis process is typically viewed as an iterative series of steps. The major steps have been described in various ways. We characterize the process in five basic steps:
(1)Problem Structuring
(2)Deterministic Modeling
(3)Probabilistic Modeling and Data Gathering
(4)Problem Analysis
(5)Communication of Results.

The objective of the problem structuring phase is to develop a clear statement of the decision maker's alternatives, values, and uncertainties. This step is a process for clarifying ideas about the nature of the decision and the major issues and uncertainties.

The deterministic phase of the decision analysis process has three major objectives. One is to develop a quantitative model of the structural relationships among decisions, uncertainties, and outcomes. We refer to this as an "outcome" model. A second objective is to develop a model that reflects the decision maker's risk attitude and preferences over a varicty of outcome measures (if there is more than one type of outcorne). This second model calculates a single numeraire for describing the value of all outcomes. We refer to this as a "value model." Finally, a third objective is to determine the sensitivity of outcomes to model variables thought to be uncertain. This step helps to reduce the number of variables that are treated formally in the probabilistic assessment and modeled as uncertainties.

The purpose of the probabilistic phase is two-fold: (1) to develop a model of the probabilistic relationships (i.e., dependence and independence) among uncertain variables and (2) to assess the probability distributions for each uncertain variable.

In the problem analysis phase, the components of the model are linked together and a formal evaluation of the problem is conducted. The "standard" outputs of a decision analysis include the following:

- the optimal policy (i.e., the best choice for each decision given each possible statt of each uncerain variable for each cnoice),

- the expected value of the optimal policy, 
- the probability distribution on the optimal policy (a risk profile represented by a cumulative distribution, mass function, or a density function for continuous variables),

The cojective of the communication phase is to promote the analyst's and ultimately the decision maker's understanding of the model results. A successful analysis requires that the model be able to support explanations of why an answer is the "right" answer.

\section{B.3. Example Analysis}

To demonstrate the decision analysis approach and its results, a simple model of the decision on energy conservation standards for new federal residential buildings has been constructed. This is an example analysis and not a complete application of the process. The model structure and input data were developed quickly without the depth of research that a decision of this importance justifies.

The example is presented through a discussion of each step in the decision analysis process:
(1) Problem Structuring
(2) Deterministic Modeling
(3) Probabilistic Modeling and Data Gathering
(4) Problem Analysis
(5) Communication of Results.

\section{Problem Structuring}

Several of the stages in decision analysis are natural in any well conducted analysis. For example, the problem structuring phase for the residential standard was covered in the initial EASIECS report. This report defines the decision -- to implement the standard or not -- and discusses such critical issues as added capital costs, energy savings, and increasing energy costs. The body of this report extends the problem structure by raising the issue of the indirect costs of fossil fuel use.

In this appendix, we will extend the analysis still further by considering two additional issues, effects of the standard on non-federal housing and the cost of program administration. A federal energy conservation standard for residential housing may have a significant effect on non-federal housing construction by providing a clear demonstration of the economic benefits of energy conservation. Perhaps because such effects are very uncertain, this factor has not been previously considered; however, decision analysis provides a framework for explicitly considering this uncertainty in the analysis. Similarly, the costs associated with program administration have not becn addressed. Again, this maybe because of the uncertainty of such costs. 


\section{Deterministic Modeling}

The next steps in the analysis are to develop the outcome and value models. These steps have been largely completed in the body of this report. In this study, the outcome model is the method for calculating the flow of expenditures over time. This has been carefully detailed in the body of the report and the same methods will be used in this appendix with slight modifications. These modifications are:

- A one hundred year horizon will be used to reduce calculations.

- The cost for administration will be included as a payment in the first year.

- In addition to federal housing, benefits from some fraction of non-federal housing will be included.

Three value models will be used in this appendix. In the first, the cash flow will be analyzed with standard Net Present Value discounting; in the second, the cash flow will be analyzed with Relative Value discounting; and, in the third, the cash flow will be analyzed with Relative Value discounting and the benefit, to cost ratio. The merits of these different measures of value are discussed in Sections 3 and 5 of this report. This analysis will not adjust values for risk. This simplifies the analysis and is probably appropriate for a decision that will not impose major risks on the national economy.

Having established the outcome and value models, the next step in a full analysis would be sensitivity analysis. In sensitivity analysis, base case inputs are specified and a base case outcome and decision are determined. Next, each input is varied from a low to high value and the outcomes examined to determine if the decision should change. If varying an input changes the decision, it is called a sensitive variable. The effect of uncertainty in each sensitive variable is then examined in the probabilistic phase of the analysis.

In this example, a base case will be presented but sensitivities will not be examined. We will simply pick four variables to illustrate the probabilistic analysis. These variables will be:

- The indirect costs

- The pattern of housing survival

- The percent of non-federal housing influenced by the program

- The cost of administering the program.

The base case inputs are shown in Table 1. Most of these inputs have been discussed in the body of this report; however, descriptions of the following may be useful:

- Non-federal built. This is an estimate of the number of non-federal residential units to be constructed in 1986 through 1990. The source is Energy Conservation Goals for Buildings, A Report to Congress of the United States, May 1988, U.S. Department of Energy, DOE/CE-0224. 
- Building life. To simplify the analysis, the distribution of housing lives is approximated with linear segments. Tigure 1 shows the curves used in this analysis. The bottom scale shows the number of years after construction and the left scale shows the percent of units remaining at this point in time. The three solid line curves are three different patterns of housing stock retirement that will be used in this analysis. The dotted line shows the curve used in the body of this report. The nominal case approximation produces the heavy solid curve in the figure; note that the nominal curve matches the data presented in body of the report closely. In the nominal case, $69.3 \%$ of houses last 33.5 years or longer, $29.0 \%$ last 75 years or longer, and $13.5 \%$ last 100 years or longer.

- \% Non-fed built to standard. This is the percent of the non-federal residential units built to the federal standard due the demonstration effect. The value was chosen by the author to illustrate the analysis; it would more properly be determined by an expert with experience in demonstration energy programs and their effectiveness.

- Relative impact on costs. The model allows for lesser energy savings in non-federal residential units influenced by the standard. The value was set at $100 \%$ for this analysis.

- Relative value rate. These are the parameters that control the relative value discounting. They correspond to a 7\% initial discount rate and a temporal mid-value of 15 years; the values are further explained in the body of this report.

- Administrative costs. Again, this value was chosen by the author to illustrate the analysis; it would more properly be determined by an expert in program administration.

The base case results are that implementation of the standard would have a Net Present Value of $\$ 0.46$ billion, a Relative Value of $\$ 1.09$ billion, and a Relative Value net benefit to initial cost ratio of 11.7. This is a substantially larger effect than indicated in the EASIECS report or implied by the analysis in Section 4 of this report. The Net Present Value and Relative Value numbers are larger than the EASIEC's estimates due both to the inclusion of indirect fuel costs and the demonstration effect on non-federal housing. The numbers are larger than those in Section 4 due to the demonstration effect on non-federal housing. The benefit to cost ratio is somewhat lower than that found in Section 5 due to the inclusion of administrative costs and the somewhat shorter time horizon used. 


\section{BASE CASE INPUTS}

Base Data

Average Net Differences

Between Standard and Common Buildings

Ave. Capital Cost Dif. 1

$\$ \quad 1059.69$

Ave. Capital Cost Dif. 15

$\$$

489.85

Ave. Capital Cost Dif. 18

$\$$

86.07

Ave. Electric Saving Dif.

kwh

$-2185.86$

Ave. Gas Saving Dif.

therm

$-20.14$

Ave. LP Saving Dif.

gal

$-27.87$

Ave. Oil Saving Dif.

gal

$-10.95$

Average Energy Costs

Electricity

$\$ / \mathrm{kwh}$

0.0664

Gas \$/therm

0.559

LP

$\$ / \mathrm{gal}$

0.629

Oil \$/gal

0.841

Price Escalation Factors

Ave. Energy Cost Increase

$\% / y r$

$3.425 \%$

Indirect Fuel Costs

2.4

Building Life

$\mathrm{yr} / 33.5$

$69.3 \%$

$\mathrm{yr} / 75.0$

$29.0 \%$

$\mathrm{yr} / 100.0$

$13.5 \%$

Federal Built

\#

18500

$\%$ Fed built to standard

$\%$

$100.00 \%$

Non-Federal Built

\#

$8,000,000$

$\%$ Non-Fed built to standard

$\%$

$0.50 \%$

Relative Impact on Costs

$\%$

$100.00 \%$

Discount rate

$\%$

$7.00 \%$

Relative value rate

13.29

Program administration cost 
Figure 1: Building Lives

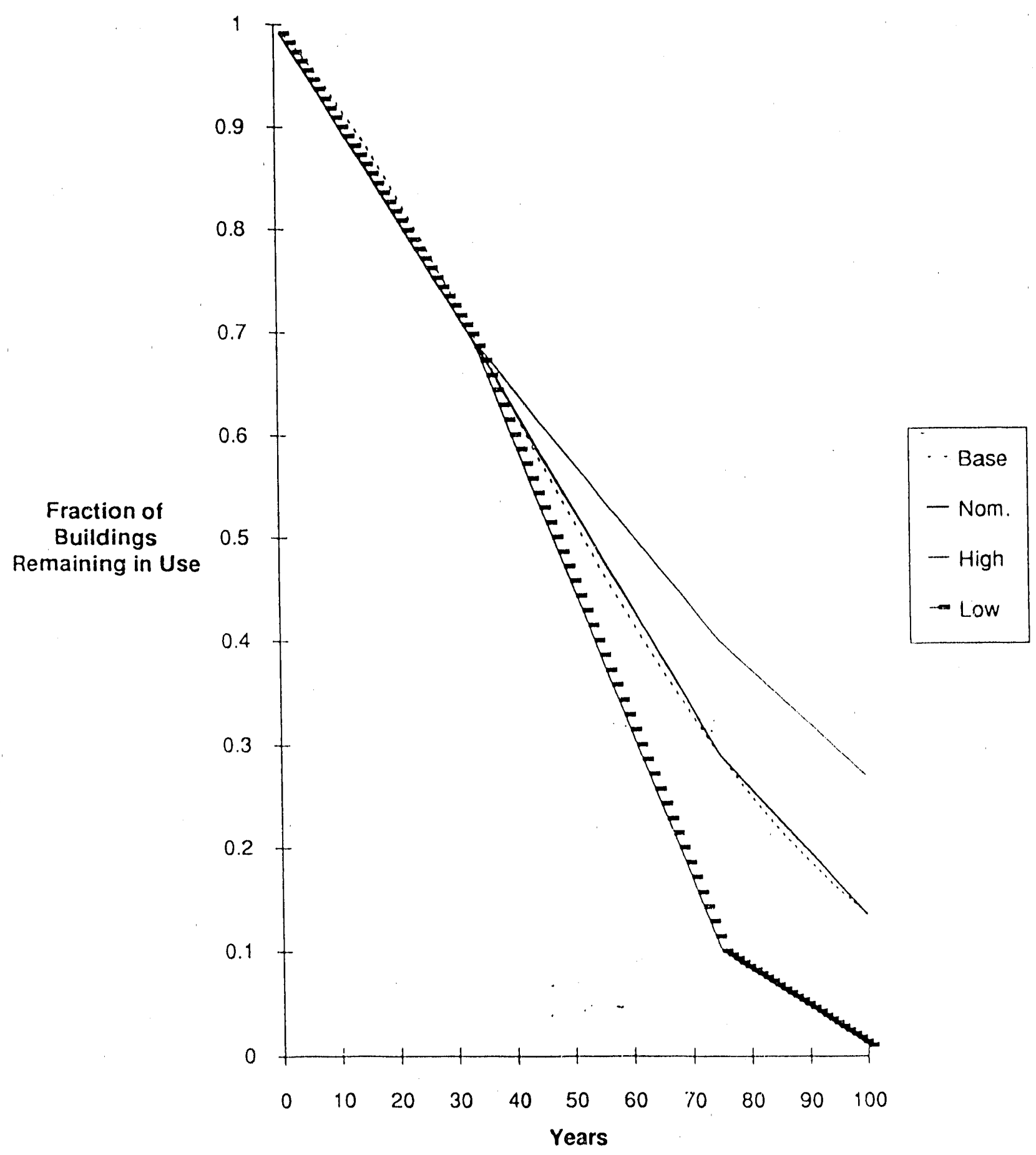




\section{Probabilistic Modeling and Data Gathering}

The probabilistic model describes the following features of the problem:

- Decision alternatives

- Possible outcomes of uncertain events or values of uncertain variables

- Sequence of decision making and resolution of uncertainty

- Probabilities for uncertain events or variables -- these probabilities reflect any dependence on prior decisions on uncertainties.

The probabilistic model is often represented in a decision tree, as in Figure 2. In the decision tree, the following graphical representations are used:

- Decisions -- rectangles

- Uncertainties -- ovals

- Outcomes -- hexagons.

The decision is to implement or not implement the standard. The possible outcomes of the four uncertain events appear on the branches of each uncertainty node -- an oval in the tree. The high, medium, and low curves for housing survival are described in Figure 1. As with the base case, the values and probabilities for the non-federal built to standard and the cost of administering the program are examples supplied by the authors. They would more properly be supplied by experts on these subjects.

The sequence of decision making and learning is very simple in this model because there is a single decision. The decision is made prior to learning about the outcome of any uncertainties. The order of the uncertainties is independent.

\section{Problem Analysis}

The problem analysis was carried out using the DPL decision analysis language. DPL determines the probability and value of each final outcome along the eighty-two paths through this simple decision tree. It then calculates the expected value of the outcome based on these results. The calculation requires only a few seconds. 

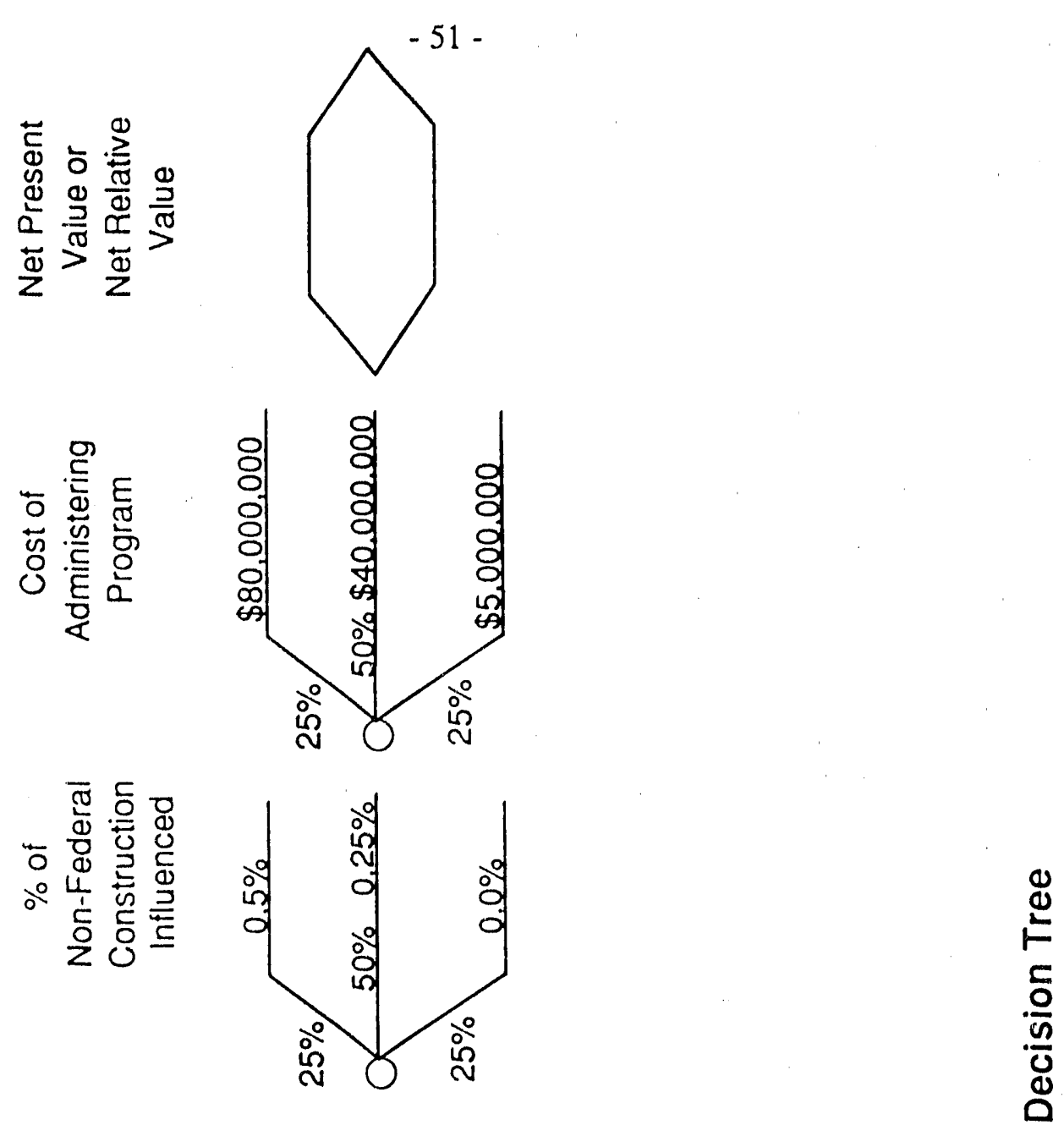

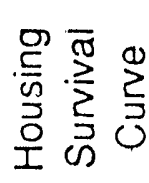

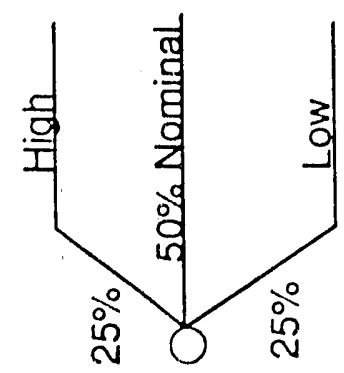

iั

竞
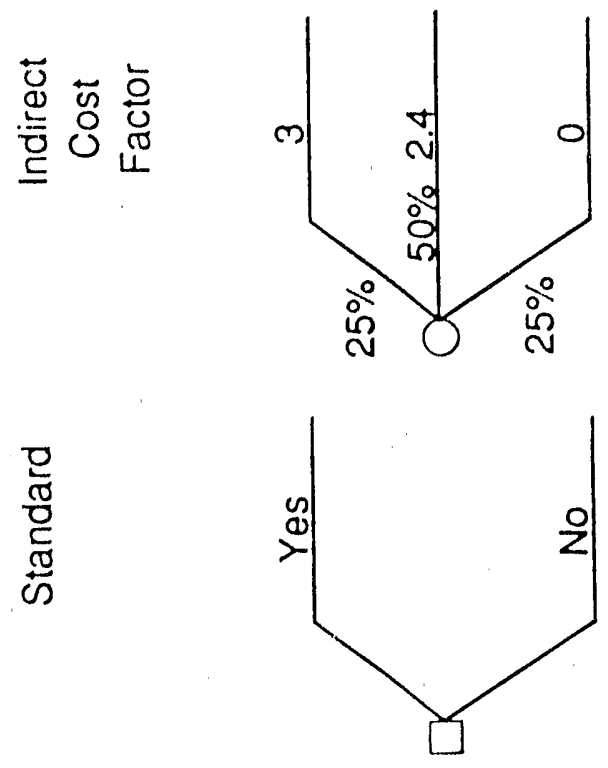


\section{Communication of Results}

The optimal policy based on this analysis is to implement the standard. The expected value of this policy is $\$ 0.24$ billion with Net Present Value discounting and $\$ 0.63$ billion with Relative Value discounting. The expected Relative Value net benefit to initial cost ratio is 9.5 . The Net Present Value and Relative Value figures are almost $50 \%$ higher than those implied by the analysis in Section 4 of this report. The major reason for this increase is the consideration of the possible effects on non-federal housing. The larger housing base does not affect the benefit to cost ratio. This ratio is smaller than the ratios found in the report due to the inclusion of initial program administration costs.

Figures 3, 4, and 5 present the cumulative probability curves for the Net Present Value, Relative Value, and Relative Value net benefit to initial cost ratio. The discounted costs minus benefits are shown at the bottom of the value graphs and probability is shown on the left of the graphs. In Figure 5, the benefit to cost ratio is at the bottom and probability is again shown on the left. To read the graphs, we first pick a level of returns, for example $\$ 0.20$ billion on the NPV graph. Next, we move up to the curve and read across to determine the probability that the return will be less than $\$ 0.20$ billion. On the NPV graph, this probability is approximately $44 \%$. The graph provides information on the full range of possible outcomes for this measure of performance.

From Figure 3, the NPV graph, we can determine that using this value model, the worst case is a loss of $\$ 0.031$ billion and the best case is a gain of $\$ 0.58$ billion. The probability of the program having negative value is $1.5 \%$.

From Figure 4, the Relative Value graph, we can determine that, using this value model, the worst case is a gain of $\$ 0.053$ billion and the best case is a gain of $\$ 1.41$ billion. The probability of the program having a negative value is insignificant.

From Figure 5, the Relative Value net benefit to initial cost graph, we can determine that, using this value model, the worst case is a 1.5 benefit to cost ratio and the best case is an 22.0 benefit to cost ratio. The probability of the program having a benefit to cost ratio less than one is insignificant.

\section{SUMMARY}

This analysis has been purely illustrative; in a proper, analysis all of the input data would have been collected from experts in the area of federal energy policy and housing. However, this example illustrates each of the steps in the decision analysis process and how they could be implemented.

The importance of this example is to demonstrate how uncertain information can logically be integrated into decision making. It may also emphasize the importance of including uncertain factors in an analysis, if a complete and unbiased view of the future is to be used in decision making. 
$-53$.

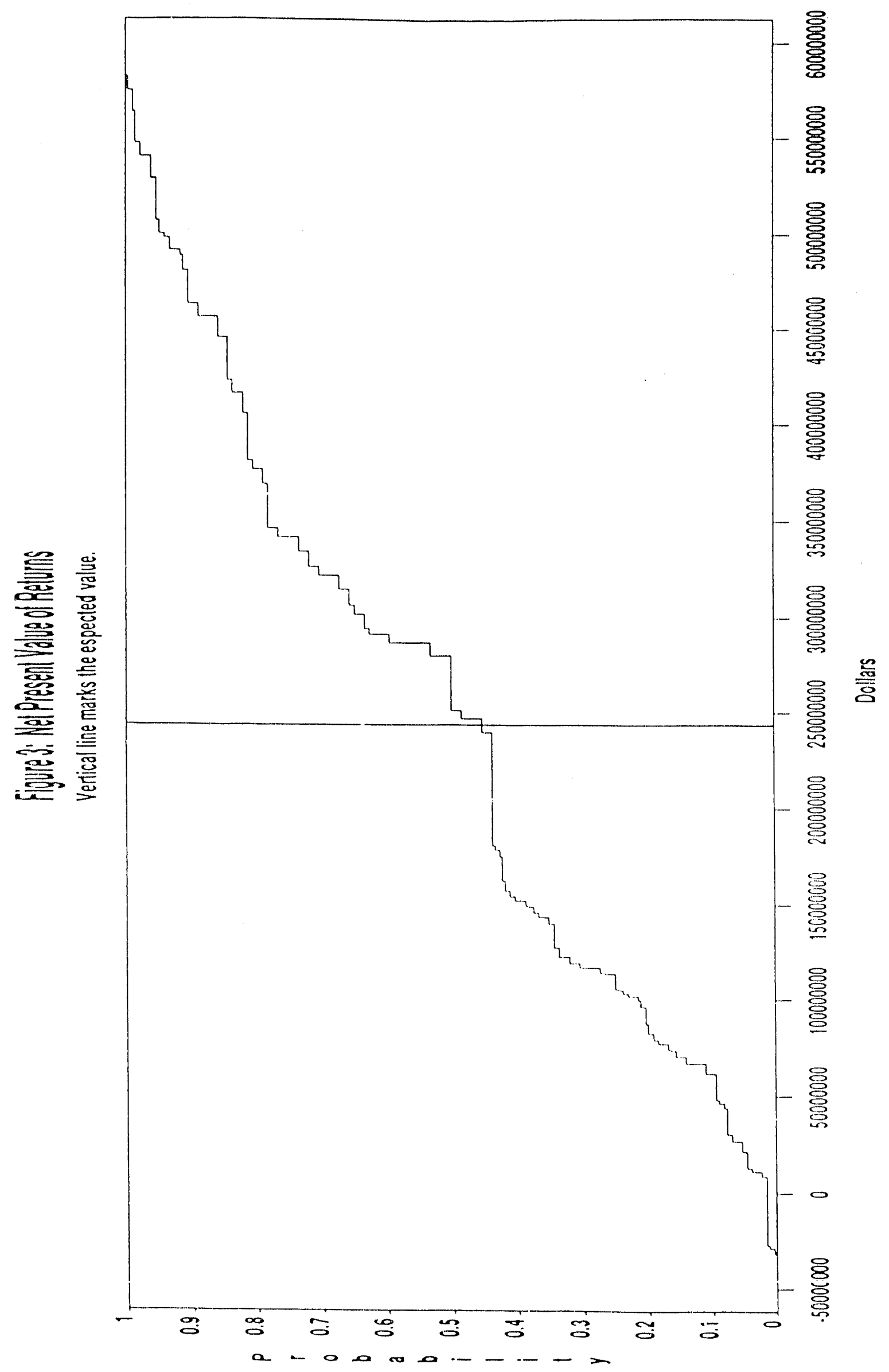




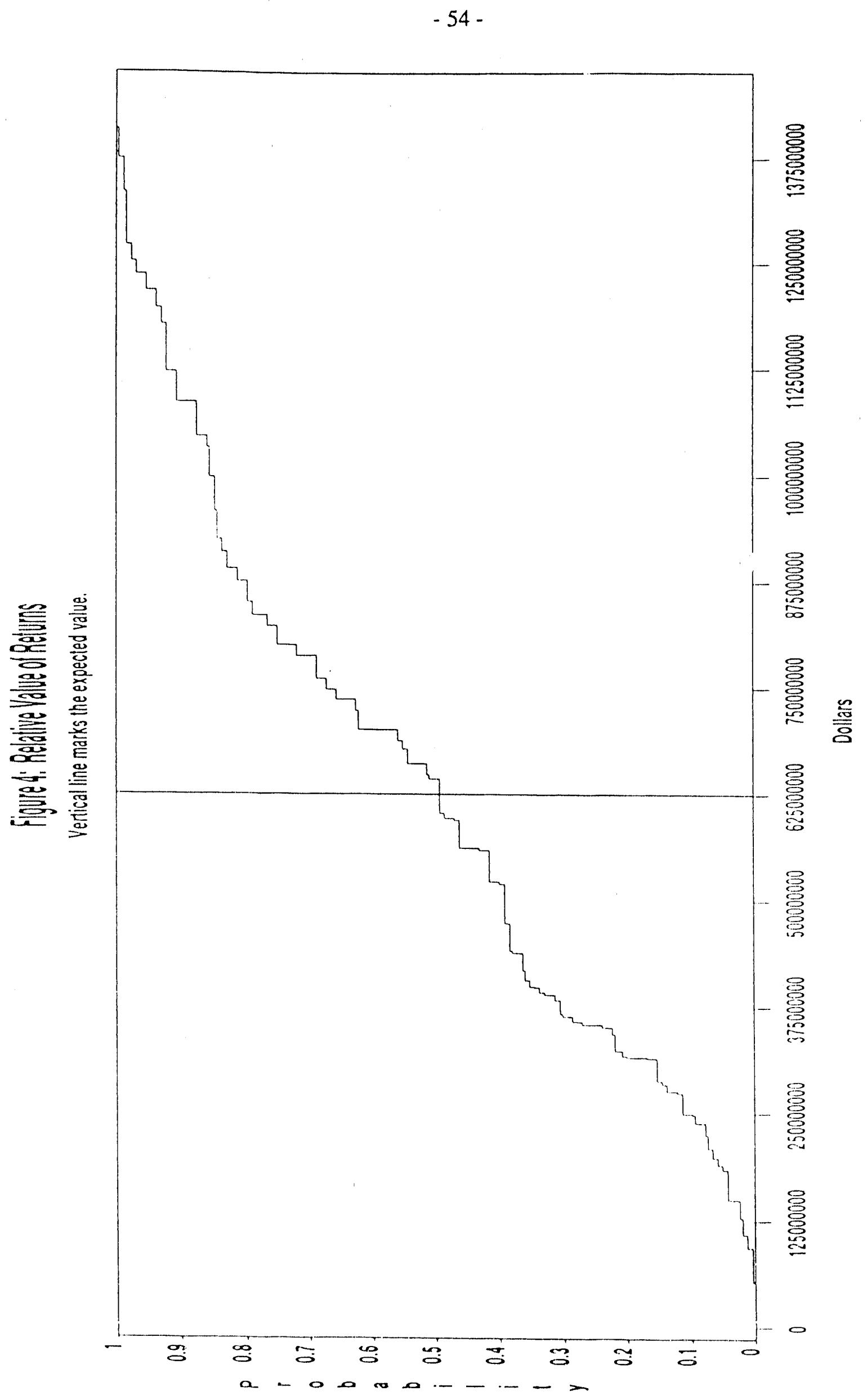




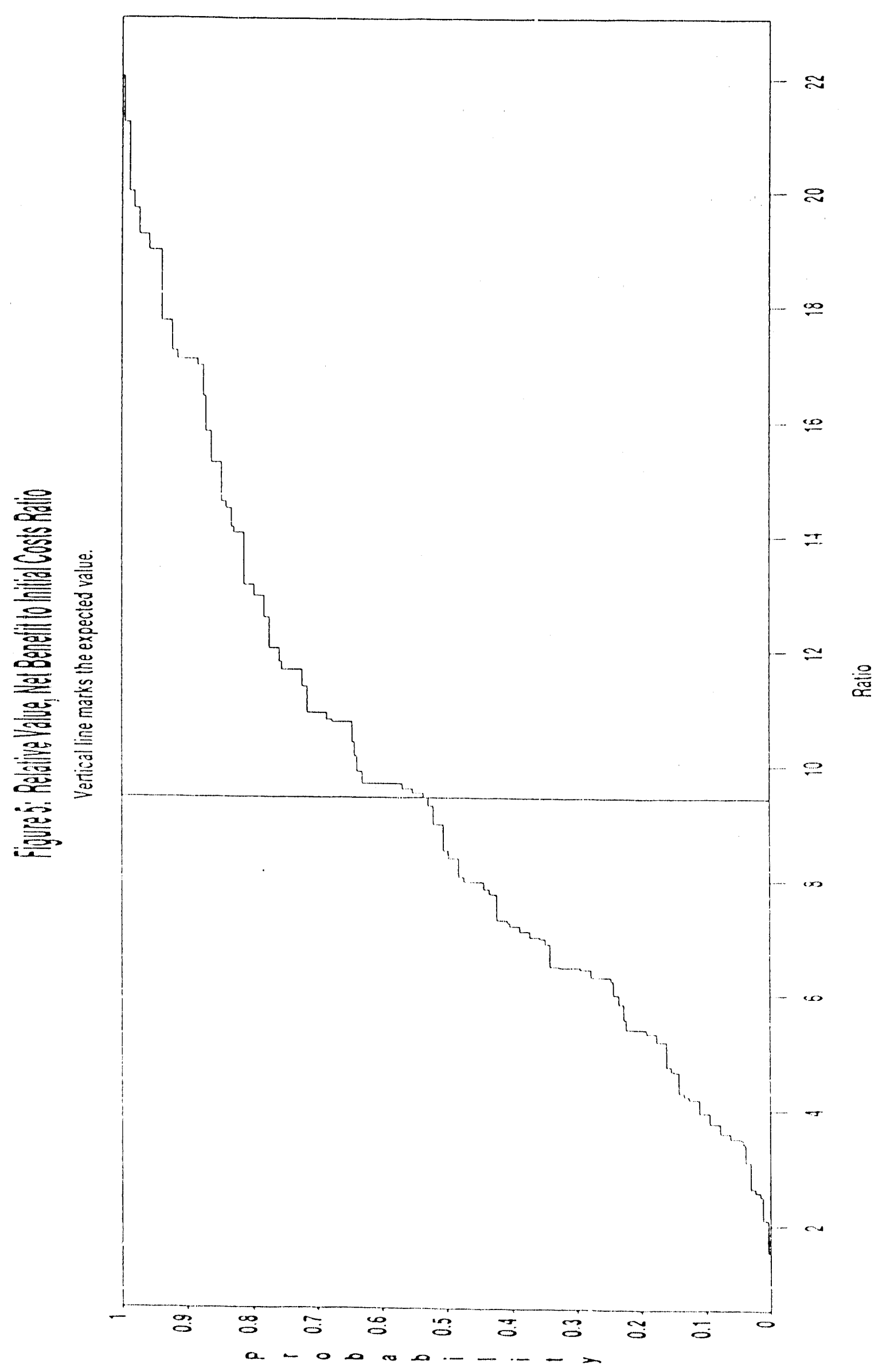




\section{References:}

Howard, R.A., and J.E. Matheson, eds. 1981. The Principals and Applications of Decision Analysis, Vols I and II. Strategic Decisions Group, Menlo Park, CA.

Raiffa, H. 1968. Decision Analysis. Addison-Wesley, Reading, Mass. 

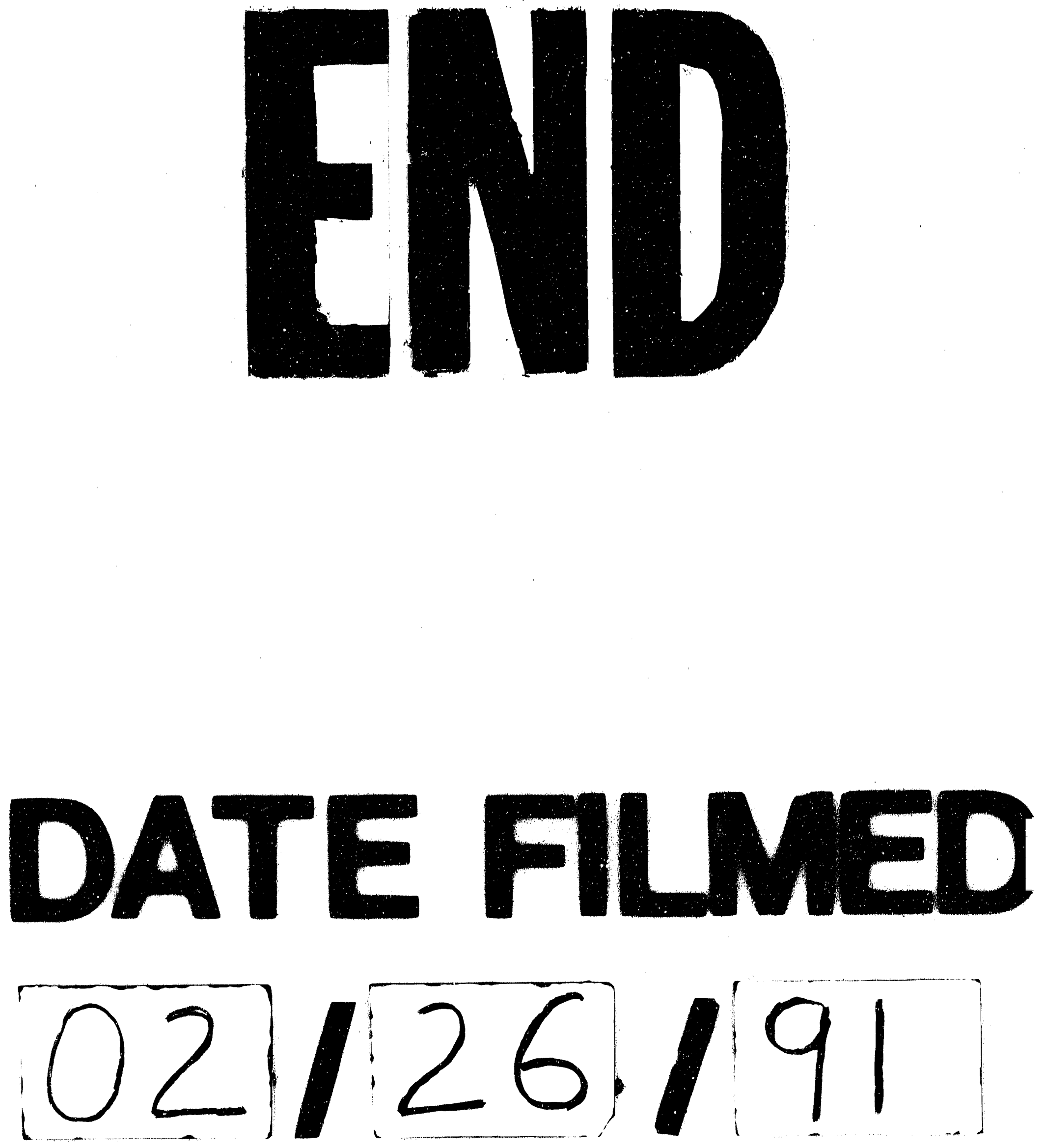
